\title{
FRONTEIRAS ESTOCÁSTICAS, DUALIDADE NEOCLÁSSICA \\ E EFICIÊNCIA ECONÔMICA NA PRODUÇÃO \\ DE FRANGOS DE CORTE
}

\begin{abstract}
OSCAR TUPY
Veterinário

Orientador: Prof. Dr. Geraldo Sant'Ana de Camargo Barros

Co-orientador: Prof. Dr. Ricardo Shirota

Tese apresentada à Escola Superior de Agricultura "Luiz de Queiroz", da Universidade de São Paulo, para obtenção do título de Doutor em Ciências, Área de concentração: Economia Aplicada
\end{abstract}

\section{PIRACICABA}

Estado de São Paulo - Brasil

Setembro - 1996 
Dados Internacionais de Catalogação na Publicação (CIP)

DIVISĀO DE BIBLIOTECA E DOCUMENTAÇĀO - Campus "Luiz de Queiroz"/USP

\section{Tupy, Oscar}

Fronteiras estocásticas, dualidade neoclásssica e eficiência econômica na produção de frangos de corte/ Oscar Tupy. - - Piracicaba, 1996.

$91 \mathrm{p}$.

Tese (doutorado) - - Escola Superior de Agricultura Luiz de Queiroz, 1996.

Bibliografia.

1. Econometria 2. Eficiência 3. Frango de corte 4. Modelo de Cobb Douglas 5. Produção I. Título

CDD 338.176513

338.16 


\section{FRONTEIRAS ESTOCÁSTICAS, DUALIDADE NEOCLÁSSICA \\ E EFICIÊNCIA ECONÔMICA NA PRODUÇÃO \\ DE FRANGOS DE CORTE}

OSCAR TUPY

Aprovada em : 06. 02.97

Comissão julgadora:

Prof. Dr. Ricardo Shirota

ESALQ/USP

Profa. Dra. Ana Lúcia Kassouf

ESALQ/USP

Prof. Dr. Joaquim Bento de Souza Ferreira Filho

ESALQ/USP

Prof. Dr. Maurinho dos Santos

UFV

Prof. Dr. Tsunehisa Tamaki

FCAVIUNESP

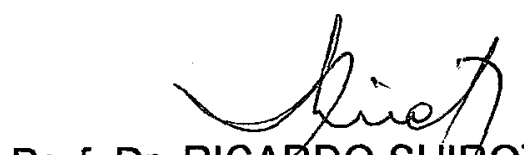

Prof. Dr. RICARDO SHIROTA

Co-orientador 
$\grave{A}$

Pery e Terezinha, in memorian

Tude, in memorian

Ligia

Clarissa

Oscar Filho

Lucas

Ana Luisa

dedico. 


\section{Agradecimentos}

À Sociedade Brasileira que com toda a sabedoria tem mantido Instituições de Pesquisa e de Aperfeiçoamento de Recursos Humanos como a EMBRAPA, USP, CAPES, CNPq, FAPESP, FAPEMIG e outras grandes instituições, fundamentais ao desenvolvimento econômico e social do Brasil;

Ao Centro de Pesquisa de Pecuária do Sudeste - EMBRAPA pela oportunidade de treinamento concedida;

Ao professor Dr. Geraldo Sant'Ana de Camargo Barros pela orientação durante todo o curso;

Ao professor Dr. Ricardo Shirota cuja co-orientação foi fundamental à conclusão do trabalho de tese;

Ao professor Pedro Valentim Marques pela minha apresentação ao Departamento de Economia e Sociologia Rural da ESALQ-USP e acompanhamento nos difíceis momentos iniciais do curso;

À professora Dra. Ana Lúcia Kassouf pelos comentários precisos que só engrandèceram o meu trabalho de tese;

Ao professor Dr. Joaquim Bento de Souza Ferreira Filho pela boa vontade em discutir aspectos fundamentais do trabalho de tese;

Aos professores Drs. Maurinho dos Santos e Tsunehisa Tamaki pela contribuição dada ao aperfeiçoamento do trabalho de tese;

À professora Dra. Roseli Aparecida Leandro do Departamento de Matemática

e Estatística da ESALQ-USP pela orientação em estatística matemática;

Ao corpo de professores do Departamento de Economia e Sociologia Rural da ESALQ/USP pelos ensinamentos ministrados;

Às Empresas Avícolas pela cessão dos dados necessários à elaboração do trabalho de tese;

Aos funcionários da ESALQ-USP pela atenção dispensada e serviços prestados durante todo o curso de pós-graduação;

Aos colegas de curso, companheiros constantes e a todos aqueles que direta ou indiretamente contribuiram para a realização deste trabalho. 
SUMÁRIO

Página

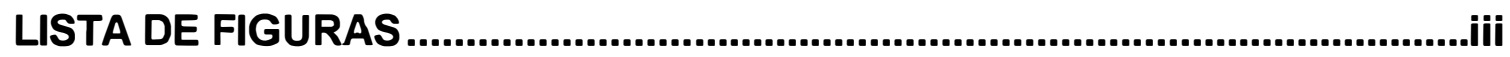

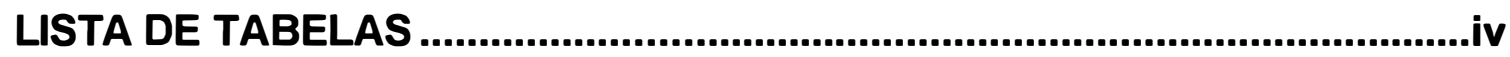

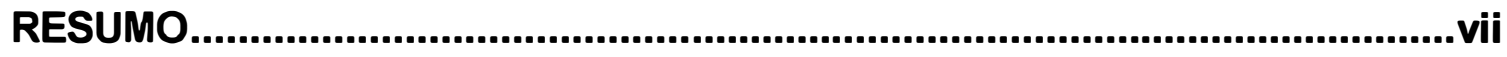

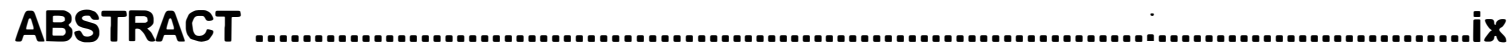

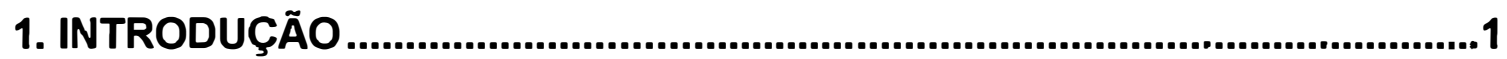

1.1. Tendências mundiais na produção, consumo e comércio

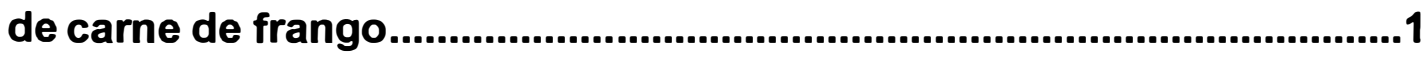

1.2. Importância do Tema .......................................................................7

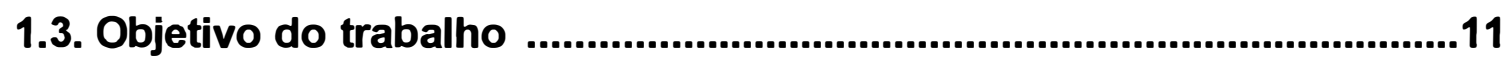

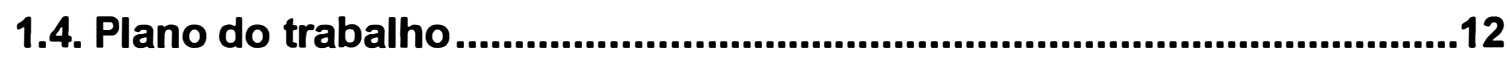

2. REVISÃO DE LITERATURA................................................................13

2.1. O conceito de eficiência econômica .....................................................13

2.2. Métodos de análise de eficiência econômica........................................17

2.3. Aplicações empiricas de análise de eficiência econômica

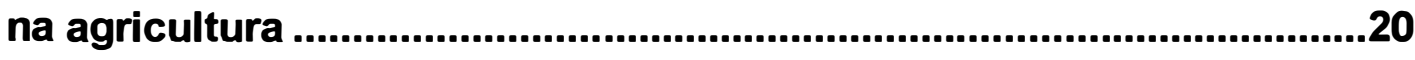

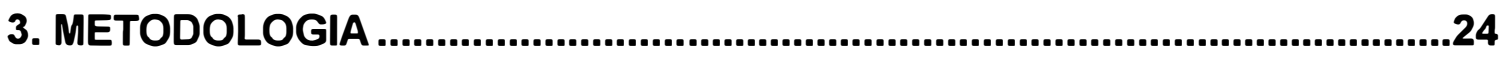

3.1. O modelo teórico...............................................................................24

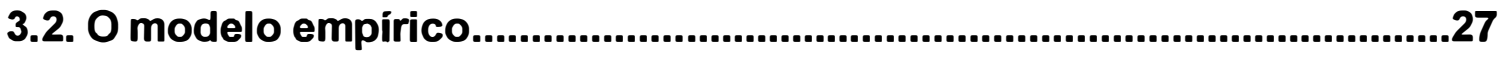

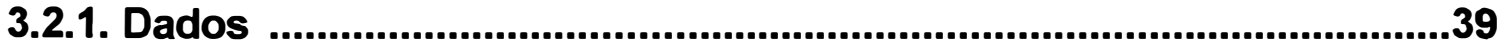

3.2.2. Descrição das variáveis do modelo ...................................................40

3.2.3. Forma funcional adotada para o modelo...........................................42

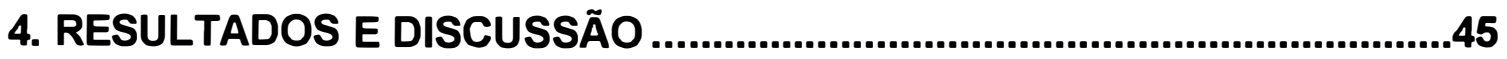

4.1. Estimação da função de custo fronteira................................................45 


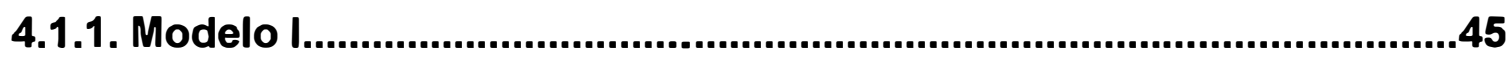

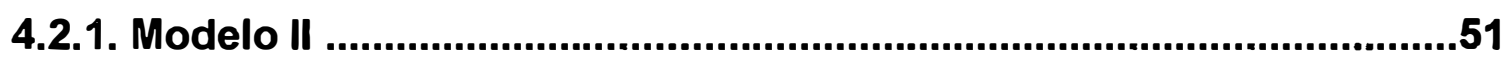

4.2. Eficiência econômica na produção de frangos de corte .....................54

4.3. Análise das relações entre estimativas de eficiência econômica e indicadores zootécnicos de eficiência em uso na produção de frangos de corte .....................................................................64

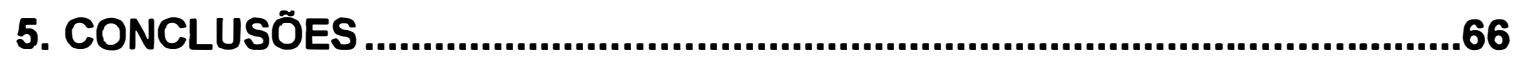

REFERÊNCIAS BIBLIOGRÁFICAS .......................................................70

APÊNDICE 1 -Evolução da eficiência econômica (EE) ao longo do tempo por empresa avícola .76

APÊNDICE 2 - Estatística descritiva das estimativas de eficiência econômica e dos indicadores zootécnicos de eficiência por empresas e para a amostra total .86 


\section{LISTA DE FIGURAS}

Página

Figura 2.1 - Representação gráfica da análise de Farrel sobre eficiência

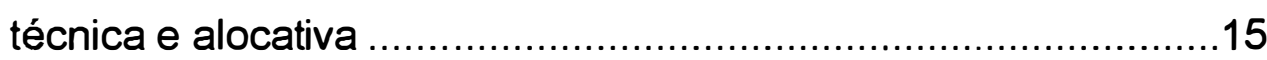

Figura 4.1 - Eficiência econômica de empresas avícolas - MIDMN ................59

Figura 4.2 - Eficiência econômica de empresas avícolas - MIDEX.................60

Figura 4.3 - Eficiência econômica de empresas avícolas - MIIEA

Figura A.1 - Evolução da eficiência econômica (EE) ao longo do tempo -

Empresa I

Figura A.2 - Evolução da eficiência econômica (EE) ao longo do tempo Empresa II.

Figura A.3 - Evolução da eficiência econômica (EE) ao longo do tempo Empresa III .79

Figura A.4 - Evolução da eficiência econômica (EE) ao longo do tempo Empresa IV .80

Figura A.5 - Evolução da eficiência econômica (EE) ao longo do tempo Empresa V. .81

Figura A.6 - Evolução da eficiência econômica (EE) ao longo do tempo Empresa VI

Figura A.7 - Evolução da eficiência econômica (EE) ao longo do tempo Empresa VII

Figura A.8 - Evolução da eficiência econômica (EE) ao longo do tempo -

Empresa VIII 84

Figura A.9 - Evolução da eficiência econômica (EE) ao longo do tempo Empresa IX .85 


\section{LISTA DE TABELAS}

Página

Tabela 1.1 - Produção de carne de frango por região (1.000 t) no periodo 1991-96

Tabela 1.2 - Evolução da produção brasileira de carne de frango em toneladas, $1970-96$ 3

Tabela 1.3 - Consumo per capita de carne de frango, por região, kg/ano, 1991-96

Tabela 1.4 - Consumo per capita de carne de frango, de bovino e de suíno, em kg, Brasil, 1970-1995 4

Tabela 1.5 - Produtividade de frangos de corte, 1930 - 2001 .5

Tabela 1.6 - Exportações de carne de frango por região (1.000 t),19911996 .6

Tabela 1.7 - Importações de carne de frango por região (1.000 t), 1991-96. .7

Tabela 3.1 - Média mensal de produção de frangos de corte por empresa no período de janeiro de 1995 a abril de 1996

Tabela 3.2 - Estatística descritiva das variáveis selecionadas para análise

Tabela 4.1 - Coeficientes estimados para a função de custo fronteira translog com especificação normal-truncada (Modelo I)

Tabela 4.2 - Coeficientes estimados para a função de custo fronteira log- linear tipo Cobb-Douglas com especificação meionormal (Modelo I) 
Tabela 4.3 - Coeficientes estimados para a função de custo fronteira log- linear tipo Cobb-Douglas com especificação exponencial (Modelo I)

Tabela 4.4 - Coeficientes estimados para a função de custo fronteira log- linear tipo Cobb-Douglas com especificação meionormal (Modelo II).

Tabela 4.5 - Estatística descritiva das estimativas de eficiência econômica obtidas com base no MIDMN, MIDEX e MIIEA

Tabela 4.6 - Correlações entre estimativas de eficiência econômica (EE) obtidas com base no MIDMN, MIDEX e MIIEA

Tabela 4.7 - Estimativa da eficiência econômica média (EE) por empresa com base no MIDMN..

Tabela 4.8 - Estimativa da eficiência econômica média (EE) por empresa com base no MIDEX

Tabela 4.9 - Estimativa da eficiência econômica média (EE) por empresa com base no MIIEA

Tabela 4.10 - Análise de correlação entre estimativas de eficiência econômica e indicadores zootécnicos de eficiência

Tabela B.1 - Estatística descritiva das estimativas de eficiência econômica e dos indicadores zootécnicos de eficiência da empresa I

Tabela B.2 - Estatística descritiva das estimativas de eficiência econômica e dos indicadores zootécnicos de eficiência da empresa II

Tabela B.3 - Estatística descritiva das estimativas de eficiência econômica e dos indicadores zootécnicos de eficiência da empresa III 
Tabela B.4 - Estatística descritiva das estimativas de eficiência econômica e dos indicadores zootécnicos de eficiência da empresa IV

Tabela B.5 - Estatística descritiva das estimativas de eficiência econômica e dos indicadores zootécnicos de eficiência da empresa $\mathrm{V}$

Tabela B.6 - Estatística descritiva das estimativas de eficiência econômica e dos indicadores zootécnicos de eficiência da empresa VI

Tabela B.7 - Estatística descritiva das estimativas de eficiência econômica e dos indicadores zootécnicos de eficiência da empresa VII 90

Tabela B.8 - Estatística descritiva das estimativas de eficiência econômica e dos indicadores zootécnicos de eficiência da empresa VIII .90

Tabela B.9 - Estatística descritiva das estimativas de eficiência econômica e dos indicadores zootécnicos de eficiência da empresa IX

Tabela B.10- Estatística descritiva das estimativas de eficiência econômica e dos indicadores zootécnicos de eficiência para todas as empresas 


\title{
FRONTEIRAS ESTOCÁSTICAS, DUALIDADE NEOCLÁSSICA \\ E EFICIÊNCIA ECONÔMICA NA PRODUÇÃO \\ DE FRANGOS DE CORTE
}

\begin{abstract}
Autor: OSCAR TUPY
Orientador: PROF. DR. GERALDO SANT'ANA DE CAMARGO BARROS

Co-orientador: PROF. DR. RICARDO SHIROTA
\end{abstract}

\section{RESUMO}

O segmento de produção de frangos de corte é básico na Indústria avícola. Esta, insere-se em um mercado competitivo, onde operar com eficiência econômica é fundamental para a sobrevivência das empresas. Assim, torna-se extremamente importante monitorar a eficiência econômica da firma, uma vez que firmas pouco eficientes serão certamente afastadas do mercado. Com esta perspectiva, o presente trabalho, estimou a eficiência econômica na produção de frangos de corte de empresas avícolas do sul e sudeste do Brasil. Nove empresas, representando aproximadamente $20 \%$ da produção brasileira de frangos de corte, foram analisadas entre janeiro de 1995 e abril de 1996. As estimativas de eficiência econômica foram obtidas utilizando-se uma abordagem dual e o método econométrico de fronteiras estocásticas. Funções de custo do tipo Cobb-Douglas na forma log-linear e com especificações meio-normal e exponencial foram estimadas. Formas funcionais flexíveis do tipo translog ou log-quadrática não se ajustaram aos dados utilizados. A eficiência econômica estimada para as empresas avícolas foi muito alta, variando entre 93 e 100\%, aproximadamente. Neste caso, 
ganhos em produtividade advirão predominantemente da introdução de novas tecnologias no segmento de produção de frangos de corte. O Índice de Eficiência Produtiva (IEP), indicador zootécnico de eficiência muito utilizado na avicultura de corte, mostrou-se positivamente correlacionado com a eficiência econômica estimada $(r=0,86)$, podendo ser utilizado como um indicador complementar desta no segmento de produção de frangos de corte. Os demais indicadores zootécnicos de eficiência exibiram uma correlação de média a baixa com a eficiência econômica estimada. 


\title{
STOCHASTIC FRONTIERS, NEOCLASSICAL DUALITY \\ AND ECONOMIC EFFICIENCY IN \\ POULTRY PRODUCTION
}

\begin{abstract}
Author: OSCAR TUPY
Adviser: PROF. DR. GERALDO SANT'ANA DE CAMARGO BARROS

Co-adviser: PROF. DR. RICARDO SHIROTA
\end{abstract}

\section{ABSTRACT}

The production of broiler is basic to the Poultry Production. It is an economic activity operating in a competitive market where economic efficiency is essential to firm survival. Thus, monitoring the firm economic efficiency becomes extremely important since low efficiency firms will certainly be pushed out of the market. This research estimates the economic efficiency (cost efficiency) in poultry production of firms in South and Southeast a Brazil. Nine firms, representing aproximately $20 \%$ of brazilian poultry production, were analysed between january 1995 and april 1996. A stochastic frontier econometric method in a dual approach was used to obtain estimates the economic efficiency. Cobb-Douglas type log-linear cost frontiers with halfnormal and exponential error specifications were estimated. The translog and log-quadratic flexible functional forms did not fit adequately to the data. The estimated economic efficiency for the firms studied was very high, varying between 93 and 100 percent, aproximately. These high economic efficiency reinforce the notion that the Poultry segment is really competitive. Operating with high economic efficiency means operating on the production and cost 
frontiers. As a consequence, productivity gains will only be possible through the introduction of new technologies. The Productive Efficency Index (PEI), a largelly used animal science indicator of effciency in poultry production, showed positively correlated to economic efficiency $(r=0,86)$. That makes the PEI a complementary indicator of economic efficiency. Other animal science indicators showed a medium to low correlation with economic efficiency. Thus, they should not be used as complementary indicators of economic efficiency in Poultry production. 


\section{INTRODUÇÃO}

\subsection{Tendências mundiais na produção, consumo e comércio de carne de frango}

O setor de carnes é composto de várias cadeias produtivas, sendo as mais importantes as de suínos, bovinos e aves. Segundo dados da FAO (1995), a produção mundial de carne suína totalizou, em 1994, mais de 76 milhões de toneladas. No mesmo ano a produção mundial de carne bovina totalizou 53 milhões de toneladas e a de aves 49 milhões de toneladas.

Em termos de organização e avanço tecnológico, a cadeia produtiva de aves supera as demais. Dentro desta cadeia, a indústria de frango consolidou-se como líder, principalmente pelos ganhos genéticos obtidos. Paralelamente, seguiram-se melhorias na nutrição e sanidade das aves, assim como no abate, nos equipamentos e instalações.

A produção mundial de carne de frango passou de 26 milhões de toneladas em 1991 para 31,8 milhões de toneladas em 1995. Poderá chegar a 34 milhões de toneladas em 1996, conforme previsões do Departamento de Agricultura dos Estados Unidos (Tabela 1.1).

Por região do mundo, os aumentos na produção de carne de frango, no período 1991 - 1995 foram de 46\% na América do Sul, 32,81\% na Ásia, 27,34\% na América do Norte, 23,94\% na África, 16,03\% no Oriente médio, $12,79 \%$ na Oceania e $11,45 \%$ na União Européia. A Europa Oriental, neste mesmo período, exibiu uma redução da ordem de $40,71 \%$ na sua produção.

No Brasil, a produção de carne de frango elevou-se de um total de 217.000 toneladas em 1970 , para 4.088 .000 toneladas em 1995 , com previsão de 4.500 .000 toneladas em 1996 (Tabela 1.2). No periodo 19901995, o aumento na produção brasileira de carne de frango foi de 1.460 .254 
toneladas, o que corresponde a uma elevação da produção da ordem de $55,57 \%$. Entre 1970 e 1995 o aumento na produção foi de aproximadamente $1784 \%$.

Tabela 1.1 - Produção de carne de frango, por região, em 1991, 1995 e 1996, em $1.000 \mathrm{t}$.

\begin{tabular}{l|ccc}
\hline \multicolumn{1}{c||}{ Região $^{\mathrm{a}}$} & \multicolumn{3}{c}{ Ano } \\
\cline { 2 - 4 } & 1991 & 1995 & $1996^{\mathrm{b}}$ \\
\hline \hline América do Norte & 10.253 & 13.056 & 13.900 \\
União Européia & 4.688 & 5.225 & 5.163 \\
Ásia & 3.971 & 5.274 & 5.767 \\
América do Sul & 3.669 & 5.357 & 5.997 \\
Europa Oriental & 1.997 & 1.184 & 1.185 \\
África & 710 & 880 & 915 \\
Oriente Médio & 418 & 485 & 493 \\
Oceania & 383 & 432 & 455 \\
\hline \hline TOTAL & 26.089 & 31.893 & 33.667 \\
\hline \hline
\end{tabular}

Fonte: Associação Paulista de Avicultura (1995).

${ }^{a}$ Os dados por região referem-se apenas a países com produção acima de 1.000 toneladas.

${ }^{\mathrm{b}}$ Previsão.

O consumo mundial de carne de frango poderá atingir, em 1996, aproximadamente $24 \mathrm{~kg}$, per capita ano, conforme previsões do Departamento de Agricultura dos Estados Unidos. As regiões de maior consumo per capita em 1995 foram: Oriente Médio, América do Norte, Oceania, Ásia, América do Sul, União Européia, Europa Oriental e África (Tabela 1.3).

Os aumentos no consumo per capita por região, no período 1991 1995 foram de 40,61\% na América do Sul, 22,82\% na América do Norte, 
$22,60 \%$ na Ásia, $15,89 \%$ na África, $8,38 \%$ na União Européia, $7,87 \%$ no Oriente, e $5 \%$ na Oceania. A Europa Oriental, neste mesmo período, exibiu uma redução no consumo per capita da ordem de $7,23 \%$.

Tabela 1.2 - Evolução da produção Brasileira de carne de frango em toneladas, $1970-96$.

\begin{tabular}{cc}
\hline Ano & Produção \\
\hline \hline 1970 & 217.000 \\
1975 & 519.000 \\
1980 & 1.200 .000 \\
1985 & 1.482 .507 \\
1990 & 2.627 .746 \\
1995 & 4.088 .000 \\
$1996^{\mathrm{a}}$ & 4.500 .000 \\
\hline \hline
\end{tabular}

Fonte: Associação Paulista de Avicultura (1995).

a previsão.

No Brasil, a evolução do consumo per capita de carne de frango, de bovino e de suíno, no período 1970-1995, pode ser observada na Tabela 1.4. Neste período, esse consumo passou de $2,3 \mathrm{~kg} / \mathrm{habitan̆te,} \mathrm{em} \mathrm{1970,} \mathrm{para}$ $23,0 \mathrm{~kg} / \mathrm{habitante}$ em 1995, o que corresponde a um aumento da ordem de $900 \%$. O consumo de carne bovina aumentou $17,10 \%$ no mesmo período. Por outro lado, o consumo de carne suína aumentou apenas 1,23\% entre 1970 e 1995. 
Tabela 1.3 - Consumo per capita de carne de frango em kg/ano, por região, em 1991,1995 e 1996.

\begin{tabular}{lccc}
\hline \multicolumn{1}{c}{ Região $^{\text {a }}$} & \multicolumn{3}{c}{ Ano } \\
\cline { 2 - 4 } & 1991 & 1995 & $1996^{6}$ \\
\hline Oriente Médio & 27,32 & 29,47 & 29,96 \\
Oceania & 21,99 & 23,09 & 23,98 \\
América do Norte & 20,46 & 25,13 & 26,00 \\
Ásia & 16,94 & 20,77 & 21,24 \\
América do Sul & 14,06 & 19,77 & 20,89 \\
União Européia & 13,59 & 14,73 & 14,93 \\
Europa Oriental & 10,38 & 9,63 & 10,31 \\
África & 7,8 & 9,04 & 9,04 \\
\hline \hline
\end{tabular}

Fonte: Associação Paulista de Avicultura (1995).

${ }^{\text {a }}$ Os dados por região referem-se apenas a países com consumo acima de $1 \mathrm{~kg} / \mathrm{habitante} / \mathrm{ano}$

${ }^{\mathrm{b}}$ Previsão.

Tabela 1.4 - Consumo per capita anual de carne de frango, de bovino e de suíno, em kg, no Brasil, 1970 - 95.

\begin{tabular}{cccc}
\hline \hline Ano & Frangos & Bovinos & Suínos \\
\hline \hline 1970 & 2,3 & 22,8 & 8,1 \\
1975 & 4,9 & 29,8 & 7,2 \\
1980 & 8,9 & 32,4 & 8,2 \\
1985 & 8,9 & 22,8 & 6,9 \\
1990 & 13,4 & 23,6 & 7,0 \\
1995 & 23,0 & 26,7 & 8,2 \\
$1996^{\text {a }}$ & 25,0 & 26,3 & 8,6 \\
\hline
\end{tabular}

Fonte: Associação Paulista de Avicultura( 1995). previsão. 
O aumento da produtividade na criação de frango de corte foi expressivo em termos de peso, idade de abate e conversão alimentar (Tabela 1.5). O peso e a idade de abate do frango em 1930 eram de $1,5 \mathrm{~kg}$ e 105 dias respectivamente, com uma conversão alimentar de $3,5 \mathrm{~kg}$ de ração/kg de frango produzido. Em 1989, o peso do frango atingiu 1,94 $\mathrm{kg}$ com idade de abate de 45 dias, e uma conversão de $1,96 \mathrm{~kg}$ de ração por $\mathrm{kg}$ de frango produzido. As previsões para o ano 2001 , são de que o peso do frango atinja 2,24 kg aos 41 dias de idade, com uma conversão de 1,78 kg de ração por $\mathrm{kg}$ de frango produzido.

Tabela 1.5 - Produtividade de frangos de corte , 1930, 1970, 1989 e 2001.

\begin{tabular}{cccc}
\hline \hline Ano & $\begin{array}{c}\text { Peso / frango } \\
(\mathrm{kg})\end{array}$ & $\begin{array}{c}\text { C. Alimentar } \\
(\mathrm{kg} \text { ração / kg frango) }\end{array}$ & $\begin{array}{c}\text { Idade } \\
\text { (dias) }\end{array}$ \\
\hline \hline 1930 & 1,50 & 3,50 & 105 \\
1970 & 1,80 & 2,00 & 49 \\
1989 & 1,94 & 1,96 & 45 \\
$2001^{\mathrm{a}}$ & 2,24 & 1,78 & 41 \\
\hline \hline
\end{tabular}

Fonte: Associação Paulista de Avicultura(1995).

${ }^{a}$ Previsão.

Quanto às exportações, verifica-se uma expressiva evolução entre 1991 e 1995 (Tabela 1.6), o mesmo ocorrendo com as importações (Tabela 1.7). O aumento do comércio internacional de carne de frango entre regiões neste período, foi de $91,69 \%$ nas exportações e de $108,46 \%$ nas importações . 
Em termos mundiais, as regiões que mais exportaram em 1995 foram: América do Norte, União Européia, Ásia e América do Sul (Tabela 1.6). Por outro lado, as regiões que mais importaram em 1995 foram: Ásia, União Européia, Oriente Médio e Europa Oriental (Tabela 1.7).

Tabela 1.6 - Exportações de carne de frango,(1.000t), por região, em 1991,1995 e 1996.

\begin{tabular}{lccc}
\hline \multicolumn{1}{c}{ Região $^{\text {a }}$} & \multicolumn{3}{c}{ Ano } \\
\cline { 2 - 4 } & 1991 & 1995 & $1996^{\mathrm{b}}$ \\
\hline União Européia & 957 & 1.337 & 1.322 \\
América do Norte & 577 & 1.730 & 1.846 \\
Ásia & 362 & 973 & 1.184 \\
América do Sul & 345 & 458 & 492 \\
Europa Oriental & 124 & 49 & 45 \\
Oriente Médio & 15 & 7 & 9 \\
Oceania & 2 & 9 & 10 \\
África & 1 & 5 & 5 \\
\hline \hline TOTAL & 2.383 & 4.568 & 4.913
\end{tabular}

Fonte: Associação Paulista de Avicultura (1995).

${ }^{a}$ Os dados por região referem-se apenas a países que exportaram acima de 1.000 toneladas ${ }^{\text {bPrevisão. }}$ 
Tabela 1.7 - Importações de carne de frango, (1.000t), por região, em 1991, 1995 e 1996.

\begin{tabular}{lccc}
\hline \hline \multicolumn{1}{c}{ Região $^{\text {a }}$} & \multicolumn{3}{c}{ Ano } \\
\cline { 2 - 4 } & 1991 & 1995 & $1996^{\mathrm{b}}$ \\
\hline \hline Ásia & 726 & 1.666 & 1.990 \\
União Européia & 616 & 860 & 890 \\
Oriente Médio & 204 & 762 & 758 \\
Europa Oriental & 132 & 460 & 437 \\
América do Norte & 111 & 162 & 180 \\
África & 6 & 15 & 18 \\
América do Sul & 2 & 30 & 30 \\
\hline \hline
\end{tabular}

\begin{tabular}{llll}
\hline \hline TOTAL & 1.797 & 3.746 & 4.129
\end{tabular}

Fonte: Associação Paulista de Avicultura (1995).

${ }^{a}$ Os dados por região referem-se apenas a países que importaram acima de $1.000 \mathrm{t}$.

${ }^{\mathrm{b}}$ Previsão.

\section{2 - Importância do tema}

A indústria de frango do Brasil desempenha papel importante no cenário mundial. É a segunda maior em produção e a quarta em exportação de carne de frango. Em 1995, o país produziu e exportou, respectivamente, 4.088 mil e 442 mil toneladas. Em relação ao consumo, o mercado interno exibe potencial, podendo atrair a atenção de indústrias internacionais de alta competitividade.

A estruturação da indústria de frango no Brasil ocorreu nos anos 70 , a partir de grandes empresas, sendo que parte delas já abatia suínos no sul do país. Estas empresas seguiram o modelo americano de tecnologia de 
processo produtivo e organização da produção. Integraram verticalmente quase todas as atividades complementares da cadeia produtiva, excetuando-se a produção de frango de corte e a produção de linhagens melhoradas. $\mathrm{Na}$ produção do frango de corte, os insumos ( basicamente pintos de um dia e rações) são repassados pelas empresas aos produtores integrados mediante contratos, onde a forma de produzir (tecnologia) e o volume de produção (escala) são determinados. Quanto às linhagens melhoradas para produção do frango de corte, o suprimento ocorre via importação (Rizzi, 1993).

De acordo com Rizzi, os anos 70 foram caracterizados para a indústria de frango pelo reduzido grau de diversificação, produzindo-se basicamente 0 frango inteiro. Nos anos 80 , as mudanças tecnológicas e estruturais sofridas por esta indústria foram intensas. Ocorreu o aprimoramento tecnológico no abate de algumas empresas líderes, via introdução de máquinas e equipamentos, produtos recortados e o lançamento de novos produtos, diversificação da produção a partir da mesma base tecnológica (utilização de subprodutos originados da mesma cadeia produtiva), intensificação da integração horizontal com outros tipos de carnes, aumento do grau de concentração econômica e centralização de capitais.

Comparada com a indústria de frango de países desenvolvidos, a indústria de frango no Brasil apresenta defasagem tecnológica em determinadas etapas do abate (Rizzi, 1993). Além disso, embora não seja considerada importante por muitos especialistas em avicultura, a defasagem tecnológica na produção de linhagens melhoradas é um ponto negativo no que se refere à competitividade.

Nos últimos anos, o surgimento no cenário internacional dos acordos bilaterais, regionais e mundiais como o GATT, NAFTA, MERCOSUL, TLC e outros, vêm provocando mudanças na estrutura da indústria avícola e acirrando a sua competitividade. Cresce a preocupação com a eficiência econômica do setor. As empresas estão reavaliando as suas metas e seus 
métodos para assegurarem viabilidade e competitividade. Empresas não integradas ou com menor grau de integração estão integrando-se como forma de garantir a permanência no mercado. Alianças tecnológicas e fusões de empresas, local ou regionalmente, estão ocorrendo como forma de assegurar a sobrevivência (Wright, 1995). Para este autor, não é nova a idéia de que a eficiência é a chave para a sobrevivência das empresas. A eficiência econômica terá um papel de suma importância num futuro próximo e sem ela nenhuma empresa poderá competir em um mercado aberto.

$\mathrm{Na}$ indústria, de modo geral, a preocupação com a eficiência econômica deve começar no processo de produção. Para a indústria de frango, a complexidade do processo de produção vai além da obtenção de bons resultados zootécnicos na criação. Devem ser considerados, também, os resultados econômicos. Sem eles, torna-se impossível avaliar se os custos de produção são adequados aos resultados zootécnicos obtidos. De maneira geral, as empresas avícolas conseguem bom resultado zootécnico. Contudo, não se sabe se todas elas o fazem a custos que possam dar resultados econômicos satisfatórios num mercado cada vez mais competitivo e, consequentemente, com menor margem de lucro sobre os preços de venda (Prior, 1994).

Apesar da preocupação com a eficiência ser evidente na indústria de frango, esta não tem utilizado a tecnologia disponível para análise da sua eficiência econômica. Para a indústria de frango no Brasil, inserida em ambiente competitivo, torna-se necessário analisar a eficiência econômica de todos os seus segmentos.

No segmento de produção de frango de corte, as empresas avícolas têm-se utilizado de índices zootécnicos para medir a eficiência dos seus sistemas de produção (Marques, 1991). Tais índices não levam em conta diretamente as quantidades e os preços dos insumos utilizados no processo de produção, portanto, podem não refletir a eficiência econômica dos sistemas. 
Numa outra perspectiva, a microeconomia, a econometria e a pesquisa operacional avançaram bastante no desenvolvimento de técnicas para análise de eficiência econômica de empresas (Lovell \& Schmidt, 1988).

Foram muitos os setores da economia analisados por tais técnicas, contudo nenhuma análise foi aplicada à produção de frango de corte.

De acordo com Lovell \& Schmidt (1988), a aplicação empírica de técnicas de análise de eficiência econômica a diferentes contextos é considerada um linha de estudo importante e que vem se desenvolvendo rapidamente.

Segundo Fried, Lovell e Schmidt (1993), quando altos niveis de eficiência, altos niveis de produtividade e altas taxas de crescimento da produtividade são objetivos desejados pelas empresas, torna-se importante definir e medir a eficiência e a produtividade de acordo com a teoria econômica. Pode-se assim gerar informações úteis para administradores de empresas e formuladores de políticas. Para estes autores, o desempenho de qualquer empresa é visto como uma função do estado da tecnologia e do grau de eficiência econômica, com o primeiro definindo uma relação de fronteira entre insumos e produtos e o último incorporando desperdício e má alocação de recursos relativos a esta fronteira.

Para a indústria de frango, a medida da eficiência econômica poderá ser útil para fins estratégicos (comparação com outras empresas), táticos (permitir à gerência controlar o desempenho da empresa pelos resultados técnicos e econômicos obtidos), de planejamento (comparar os resultados do uso de diferentes combinações de fatores) ou outros relacionados à administração interna da empresa.

De acordo com Bravo-Ureta \& Rieger (1991), economistas teóricos e formuladores de política têm dispensado considerável atenção ao estudo da eficiência econômica. Do ponto de vista teórico, a importância relativa dos vários componentes da eficiência econômica são colocados em 
discussão. De uma perspectiva aplicada, o seu estudo tornou-se importante porque este é o principal passo de um processo que pode conduzir a uma economia substancial de recursos. Estes recursos poupados têm implicações importantes para a formulação de políticas e para a administração da empresa. Os ganhos em eficiência, segundo os autores, são particularmente importantes para as empresas em períodos de stress financeiro e em ambientes competitivos.

A estimativa do nível de eficiência econômica de uma empresa pode ajudar na decisão sobre como melhorar a sua eficiência atual ou desenvolver novas tecnologias para aumentar a produção com racionalidade. Pode ser útil também para o reconhecimento do gap entre o potencial de produção de uma tecnologia e o atual nivel de produção obtido (Kalirajan, 1982).

Segundo Lovell (1993), tanto a eficiência quanto a produtividade são indicadores de sucesso, medidas de desempenho através das quais as unidades produtivas são avaliadas. Somente medindo a eficiência e a produtividade e separando os seus efeitos dos efeitos do ambiente de produção, pode-se explorar hipóteses relacionadas a fontes de diferenças entre eficiência e produtividade. A identificação destas fontes é essencial para a instituição de políticas públicas e privadas.

\section{3 - Objetivo do trabalho}

$\mathrm{Na}$ teoria sobre a eficiência econômica da firma, uma empresa pode ser considerada eficiente no produto, na utilização dos insumos ou em ambos. A eficiência no produto pode ser analisada a partir do conceito de eficiência de escala. A eficiência na utilização dos insumos pode ser analisada a partir dos conceitos de eficiência técnica, alocativa e total (técnica $x$ alocativa ou econômica). Dada a amplitude do assunto, no presente trabalho, o enfoque 
foi dado basicamente à eficiência econômica na utilização dos insumos. Portanto, o objetivo deste trabalho é estimar a eficiência econômica, de empresas avícolas no segmento de produção de frango de corte.

\section{4 - Plano de trabalho}

Além da introdução, este trabalho está estruturado em mais quatro capítulos. No capítulo 2 ou revisão de literatura, aborda-se três tópicos essenciais: o conceito de eficiência econômica da firma, os métodos utilizados para análise de eficiência e os principais trabalhos empíricos publicados sobre o assunto na agricultura. No capítulo 3 ou metodologia explicita-se o modelo teórico e o modelo empírico para análise da eficiência econômica na produção de frangos de corte. $O$ capítulo 4 apresenta os resultados obtidos e as análises pertinentes e o capítulo 5 aponta as conclusões do trabalho. 


\section{REVISÃO DE LITERATURA}

\section{1 - O conceito de eficiência econômica}

De acordo com Lovell (1993), sempre que se discute sobre a performance de uma unidade produtiva, esta é descrita como sendo mais ou menos eficiente ou mais ou menos produtiva. A produtividade de uma unidade de produção é entendida pelo autor como a relação entre as quantidades de seus produtos e insumos. Tal relação é fácil de computar se a unidade produtiva usa um único insumo para produzir um único produto. Contudo, o normal é a utilização de vários insumos para produzir um ou mais produtos. No caso de vários produtos, estes deverão ser agregados no numerador de alguma maneira economicamente apropriada, o mesmo devendo ser feito para os insumos no denominador. Assim, a produtividade permanecerá como a relação de dois escalares. Para Lovell (1993), a produtividade varia devido a diferenças na tecnologia de produção, na eficiência dos processos de produção e no ambiente em que a produção ocorre, Quanto à eficiência de uma unidade produtiva, Lovell a entende como uma comparação entre valores observados e valores ótimos de insumos e produtos. Esta comparação pode assumir a forma de relação entre a quantidade do produto obtido e o seu nivel máximo, dada a quantidade do insumo utilizada ou a relação da quantidade de insumo utilizada e o seu mínimo requerido para produzir, dada a quantidade de produto obtida ou alguma combinação dos dois. Nesta comparação o ótimo é definido em termos de possibilidades de produção e a eficiência é técnica. 0 ótimo pode também ser definido em termos do objetivo comportamental da unidade produtiva. Neste caso a eficiência é econômica e é medida comparando o custo, lucro ou receita observados, com o custo, lu ro ou receita ótimos. 
Os estudos sobre eficiência em economia têm como marco o trabalho pioneiro de Farrell (1957). O autor se concentrou na medição da eficiência na utilização dos insumos. Para definir a eficiência, Farrell (1957) tomou, como exemplo, uma firma empregando dois insumos $x_{1}$ e $x_{2}$ para produzir um único produto $\mathrm{y}$. $\mathrm{A}$ tecnologia de produção foi resumida por uma função de produção linearmente homogênea, $y=f\left(x_{1}, x_{2}\right)$. Tal função pode ser escrita como $1=f\left(x_{1} / y, x_{2} / y\right)$, permitindo que todas as informações relevantes

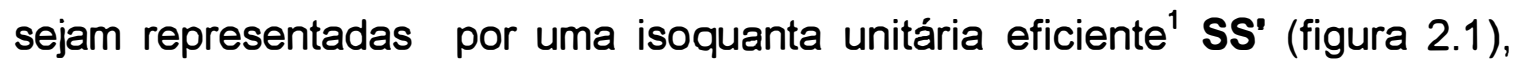
caracterizando a tecnologia de fronteira. Considerando que a firma observada utiliza $\left(x_{1}^{0}, x_{2}{ }^{0}\right)$ para produzir $y^{0}$, o ponto $\mathrm{A}$ na figura 2.1 representa $\left(x_{1}^{0} / y^{0}, x_{2}^{0} / y^{0}\right)$. Por definição, nenhuma firma pode ficar abaixo de SS'. A razão entre as distâncias da origem da figura 2.1 ao ponto $B$ e ao ponto $A$, ou seja, OB/OA mede a (in)eficiência técnica, que é a razão dos insumos necessários para produzir $y^{0}$, em relação aos insumos utilizados.

Considerando que a linha $\mathbf{W} \mathbf{W}$ é a curva de isocusto que representa a razão de preço dos insumos na figura 2.1 , então a razão entre as distâncias da origem da figura 2.1 ao ponto $\mathbf{C}$ e ao ponto $\mathbf{B}$, ou seja, OC/OB mede a (in)eficiência alocativa, uma vez que o custo do ponto $\mathbf{C}$ é o mesmo que aquele do ponto $\mathbf{E}$, alocativamente eficiente. $\mathbf{O}$ custo do ponto $\mathbf{C}$ é menor do que aquele do ponto $\mathbf{B}$, tecnicamente eficiente, mas alocativamente ineficiente. Finalmente, a relação OC/OA mede a eficiência total ou eficiência econômica.

\footnotetext{
${ }^{1}$ Segundo Forsund et alii (1980) a isoquanta unitária eficiente não é observável naturalmente, mas pode ser estimada de uma amostra de observações (possivelmente ineficientes) como A, na figura 2.1.
} 


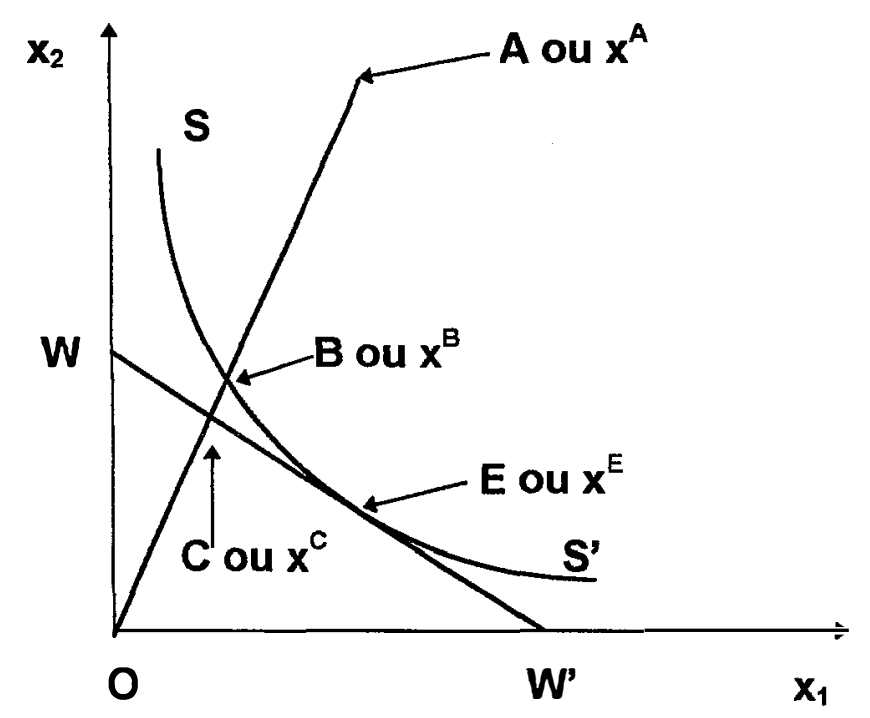

Figura 2.1 - Representação gráfica da análise de Farrel sobre eficiência técnica e alocativa

A eficiência técnica, ou seja $E T=O B / O A$ será igual a 1 se a firma no ponto A puder alcançar SS'. Por outro lado se aproximará de zero quando a distancia entre B e A aumentar. Portanto, a eficiência técnica varia de zero a 1. Operar no ponto B da figura 2.1 é ser tecnicamente eficiente, mas não representa a combinação mais lucrativa dos fatores de produção, dados os preços existentes. Portanto, a firma no ponto $\mathbf{A}$, também tem uma ineficiência preço (alocativa), que varia de zero a 1 e é causada pela proporção incorreta (não ótima) dos fatores que utiliza. A eficiência alocativa da firma no ponto $\mathbf{A}$, ou seja, EA = OC/OB, é a razão entre o custo de produzir sobre SS' com a melhor proporção de fatores e o custo de produzir sobre SS' com a proporção de fatores de $\mathbf{A}$. A eficiência econômica da firma no ponto $\mathbf{A}$, ou seja, EE = OC/OA é a combinação das medidas de ET e EA, isto é, EE = ET · EA. Esta 
medida é igual a razão entre o custo unitário de produzir com a melhor tecnologia (ponto $\mathbf{E}$ da figura 2.1) e o custo unitário de produção da firma $\mathbf{A}$ a preços correntes dos fatores ( Heathfield e Wibe, 1987).

Considerando $\mathbf{x}^{\mathbf{A}}, \mathbf{x}^{\mathbf{B}} \mathbf{e} \mathbf{x}^{\mathbf{C}}$ vetores com coordenadas nos pontos A, B e C da figura 2.1, e que $\|x\|$ é o comprimento do vetor $\mathbf{x}$, as medidas de eficiência de Farrel podem ser expressas de acordo com as equações dadas abaixo, ou seja:

$$
\begin{aligned}
& E T(A)=\frac{\left\|x^{B}\right\|}{\left\|x^{A}\right\|} \\
& E A(A)=\frac{\left\|x^{C}\right\|}{\left\|x^{B}\right\|}
\end{aligned}
$$

e,

$$
E E(A)=\frac{\left\|x^{C}\right\|}{\left\|x^{A}\right\|}
$$

A (in)eficiência técnica, resulta do uso em excesso dos fatores, na obtenção de determinado nível de produção, enquanto a ineficiência alocativa resulta do emprego de fatores em proporções erradas. Em ambos os casos o custo de produção não será minimizado (Forsund et alii, 1980). 
De acordo com Atkinson \& Cornwell (1994), uma firma é ineficiente tecnicamente se ela falha em utilizar o nível técnico mínimo de insumos dado o produto e o mix de insumos. Por outro lado, será alocativamente ineficiente quando a taxa marginal de substituição entre quaisquer dois de seus insumos não é igual a razão dos seus preços correspondentes.

\section{2- Métodos de análise de eficiência econômica}

A eficiência econômica de uma empresa, na dimensão dos insumos, pode ser obtida a partir da estimativa de uma função de fronteira. A função-fronteira é o padrão em relação ao qual será medida a eficiência da firma observada. Este é o caso das funções de produção, custo e lucro, todas definidas como conceitos de fronteira. Por exemplo, funções de produçãofronteira dão o máximo produto possivel, dado algum nível de insumos. Similarmente, uma função de custo-fronteira dá o nível mínimo de custo com o qual é possível produzir algum nível de produto, dados os preços dos insumos. Finalmente, uma função de lucro-fronteira dá o máximo lucro possível de ser atingido, dado o preço do produto e os preços dos insumos. A importância desta abordagem na análise de eficiência é que desvios destas fronteiras podem ser interpretados como ineficiência (Forsund et alii, 1980).

De acordo com Forsund et alii (1980), o montante pelo qual uma firma fica abaixo de suas fronteiras de produção e lucro e o montante pelo qual ela fica acima da sua fronteira de custo, podem ser considerados, respectivamente, como medida de ineficiência técnica, lucro ou de custo. Assim, a medida da ineficiência tem sido a principal motivação para o estudo das fronteiras, sendo que na literatura existem diferentes métodos para estimálas. 
Forsund et alii (1980) discutiram amplamente as vantagens e desvantagens dos métodos de estimação de fronteiras.

Lovell \& Schmidt (1988) consideraram quatro abordagens metodológicas: a programação pura, a programação modificada, a fronteira estatística determinística e a fronteira estocástica.

A abordagem de programação pura utiliza uma sequência de programas lineares para construir uma fronteira e para estimar a eficiência relativa a esta. A técnica foi proposta por Farrel (1957) e foi bastante desenvolvida por Charnes, Cooper e colaboradores e por Fare e colaboradores, conforme citado por Lovell \& Schmidt (1988).

O maior problema do método de programação pura resulta do fato de que a amostra de dados é envolvida por uma fronteira determinística. Consequentemente, o desvio de uma observação em relação à fronteira é atribuído exclusivamente à ineficiência. Por ser a fronteira determinística e não estocástica, nenhum ajuste é feito para variações ambientais; choques aleatórios externos, ruídos nos dados, erros de medição, variáveis omitidas, etc. Dado que o método de programação pura é não estocástico, não há um meio de se elaborar probabilidades sobre a forma e o local da fronteira ou sobre as ineficiências estimadas relativas a esta (Lovell \& Schmidt, 1988).

A abordagem de programação modificada, considerada por Lovell \& Schmidt (1988), também utiliza uma sequência de programação linear para construir fronteiras e para computar a eficiência relativa a elas. Difere da programação pura por ser a fronteira construída parametricamente. Este método também foi sugerido por Farrel (1957) e melhorado posteriormente por Aigner \& Chu (1968), Forsund \& Jansen (1977) e Forsund \& Hjalmarsson (1979). Duas são as suas desvantagens: a primeira é que a fronteira também é determinística como na programação pura, não considerando os ruídos, erros de medida, variações ambientais, etc. A segunda é sua incapacidade de tratar facilmente com produtos múltiplos (Lovell \& Schmidt, 1988) . 
A terceira abordagem em contraste com as anteriores, utiliza técnicas estatísticas para estimar a fronteira e computar a eficiência relativa a esta. O método foi proposto inicialmente por Afriat (1972) e ampliado por Richmond (1974) e Greene (1980), entre outros. Neste caso, a fronteira também é deterministica, sendo todos os desvios desta atribuídos à ineficiência da firma. Também, neste caso, nenhuma concessão é feita aos ruídos, erros de medição, etc.

A quarta e última abordagem apresentada por Lovell \& Schmidt (1988) considera uma fronteira estocástica. Utiliza técnicas estatísticas para estimar a fronteira e computar a eficiência relativa a esta. Este método foi simultaneamente proposto por Aigner, Lovell \& Schmidt (1977) e Meeusen \& Broeck (1977). A sua maior vantagem é que, ao contrário das outras abordagens, introduz um componente do erro para representar ruído, erros de medição, etc. Isto permite uma decomposição do desvio de uma observação, da parte deterministica da fronteira em dois componentes: ineficiência e ruídos. Segundo Lovell \& Schmidt(1988), nenhuma outra abordagem cuida deste fenômeno, que afeta todas as relações econômicas.

As abordagens acima diferem, portanto, no modo como especificam uma fronteira (não- paramétrica e paramétrica), no modo como a fronteira é construída (técnicas estatísticas ou de programação) e no modo como os desvios da fronteira são interpretados, ou seja, como simplesmente ineficiência ou uma mistura de ineficiência e ruído (Lovell \& Schmidt,1988).

Bauer (1990) simplificou as abordagens metodológicas acima. Para este autor, existem dois paradigmas competindo sobre como construir fronteiras. Um considera técnicas de programação matemática e o outro técnicas econométricas. A maior vantagem da programação matemática é a de que não necessita impor uma forma funcional explícita sobre os dados. Contudo, a fronteira calculada pode ser deformada se os dados são contaminados por ruídos estatísticos. A abordagem econométrica, por outro 
lado, pode manipular os ruídos estatísticos, mas impõe uma forma funcional explícita e possivelmente restritiva para a tecnologia.

As fronteiras estimadas por programação matemática têm sido bastante utilizadas na obtenção de medidas de eficiência técnica da firma e mais raramente na obtenção da eficiência alocativa (Lovell, 1993). Por outro lado, as fronteiras estimadas por técnicas econométricas, além da grande ênfase colocada nas estimativas de eficiência técnica, têm estimado também a eficiência alocativa e consequentemente a eficiência econômica da firma.

Três são os métodos predominantes na literatura que tratam da estimação da eficiência técnica e alocativa, a partir de funções econométricas de fronteira. O primeiro é o de Schmidt e Lovell (1979), que estima a eficiência técnica e alocativa a partir do sistema de equações de demanda de fatores. $O$ segundo é o de Kopp e Diewert (1982), que decompõe a eficiência econômica, dada uma fronteira de custo, em eficiência técnica e alocativa. O terceiro e mais recente é utilizado por Kumbhakar et alii (1989) e Kalirajan (1994). Neste, a eficiência técnica é estimada a partir de uma função de produção (CobbDouglas ou translog) e a eficiência alocativa é obtida a partir das condições de primeira ordem para maximização de lucro. De acordo com Greene (1993), todos os métodos apresentam pontos fortes e pontos fracos, necessitando todos eles de mais pesquisas.

\section{3 - Aplicações empiricas da análise de eficiência econômica na agricultura}

A maior parte dos estudos sobre eficiência na agricultura se concentrou na medição da eficiência técnica e na comparação dos diferentes métodos usados para estimá-la (Battese, 1992). Poucos foram os trabalhos que mediram a eficiência econômica de empresas agrícolas, sendo 
que nenhum deles foi aplicado ao setor avícola, conforme constatado por revisão de literatura.

Taylor et alii (1986) mediram a eficiência econômica de empresas rurais no Brasil, encontrando níveis muito baixos de eficiência entre fazendas participantes e não participantes do programa de crédito rural do governo. Em média, as eficiências econômicas foram de 0,125 e 0,130, respectivamente, para participantes e não participantes do programa de crédito rural. Neste trabalho, os autores derivaram analiticamente uma fronteira de custo do tipo Cobb-Douglas, para medição da eficiência econômica.

Kumbhakar et alii (1989) mediu as ineficiências técnica, alocativa e de escala de fazendas produtoras de leite nos EUA, utilizando uma função de produção fronteira tipo Cobb-Douglas e as condições de primeira ordem para maximização de lucro. Foram estimadas, separadamente, a eficiência técnica, alocativa e de escala para pequenas, médias e grandes propriedades. Em média, a porcentagem de perda no produto devido a ineficiência técnica foi de 34,66. A porcentagem de incremento no custo devido a ineficiência alocativa foi de 4,46 e a porcentagem de perda no lucro devido a ineficiência de escala foi de 9,11 para todas as propriedades estudadas.

Ali \& Flinn (1989) mediram a eficiência lucro de produtores de arroz no Paquistão, utilizando uma função de lucro translog. Contudo, a decomposição da eficiência lucro em eficiência técnica e alocativa não foi considerada. A média de perda no lucro foi de $31 \%$ neste estudo.

Ali \& Chaudhry (1990), analisando a produção de diferentes regiões agrícolas no Paquistão através de programação matemática, obtiveram medidas de eficiência econômica que variavam de 0,44 a 0,56.

Kalirajan (1990) mediu a eficiência econômica de produtores de arroz nas Filipinas, utilizando uma função de produção do tipo translog e as condições de primeira ordem para maximização de lucro. A eficiência técnica 
média estimada foi de 0,79, variando de 0,64 a 0,92 e a eficiência alocativa média foi em torno de 0,10 .

Bravo-Ureta \& Rieger (1991) mediram a eficiência econômica na produção de leite de várias fazendas nos EUA. A eficiência econômica encontrada foi de $70 \%$ para a média das fazendas analisadas. Estes autores utilizaram fronteiras de custos do tipo Cobb-Douglas, estimadas analiticamente, para obtenção da medida de eficiência econômica.

Bravo-Ureta \& Eveson (1994), utilizando a mesma metodologia de Bravo-Ureta \& Rieger (1991), mediram a eficiência econômica de fazendas produtoras de algodão e mandioca no Paraguai. Obtiveram médias de eficiência econômica de $40,67 \%$ para o algodão e de $52,26 \%$ para a produção de mandioca.

Kumbhakar (1994), trabalhando com 227 produtores no oeste de Bengala, Índia, obteve uma eficiência técnica média de 0,7546 , enquanto os niveis de eficiência alocativa foram inexpressivos. $O$ autor acima também utilizou, neste trabalho, a exemplo de Kalirajan (1990), uma função de produção do tipo translog e as condições de primeira ordem para maximização de lucro na obtenção das estimativas de eficiência técnica e alocativa.

Parik e Shah (1994) estimaram a ineficiência custo sob condições de risco na agricultura, através de uma função de custo do tipo translog e obtiveram médias de ineficiência custo com risco e sem risco de 9,8 e 11,5\%, respectivamente.

Com exceção de Ali \& Chaudhry (1990), todas as fronteiras estimadas nos trabalhos acima são econométricas, paramétricas e estocásticas com erro composto, representando ineficiência e ruídos conforme proposto por Aigner et alii (1977) e Meeusen \& Broeck (1977).

$\mathrm{Na}$ agricultura, os estudos sobre eficiência econômica da firma através de fronteiras estocásticas têm utilizado principalmente dados crosssection. Alguns trabalhos têm utilizado dados longitudinais, mas em menor 
escala, sendo as estimativas obtidas referentes apenas à eficiência técnica da firma (Battese \& Coelli, 1988 e Kumbhakar \& Haljmarson, 1993).

Taylor et alii (1986), Ali \& Flinn (1989), Bravo-Ureta \& Rieger (1991), Bravo-Ureta \& Eveson (1994) e Parik \& Shah (1994), fundamentaram na teoria da dualidade neoclássica o emprego de funções fronteira de custo e de lucro nos seus trabalhos empíricos. 


\section{METODOLOGIA}

\section{1- O modelo teórico}

Da revisão de literatura apreende-se que a medida de eficiência econômica de uma firma na dimensão dos insumos pode ser obtida como um desvio em relação a uma fronteira de produção, custo ou lucro.

A estimação de fronteiras em microeconomia pressupõe um comportamento otimizador das firmas. Este comportamento está explícito em diferentes funções objetivo utilizadas na teoria da firma (Shirota, 1995).

A transformação eficiente de insumos em produtos, por exemplo, é caracterizada por uma função de produção $f(x)$, que representa o máximo de produto possível de ser obtido a partir de um vetor de insumos $x$. Por outro lado, as funções de custo e de lucro são representações matemáticas para a solução de problemas de otimização condicionada dos agentes econômicos. A restrição imposta é a tecnologia de produção. Assim, de maneira equivalente, essas funções representam uma tecnologia de produção na medida em que embutem em sua solução as restrições impostas. Na verdade elas são capazes de expressar as características economicamente relevantes da tecnologia considerada (Varian,1992). Nesse sentido, na terminologia utilizada por McFadden, citado por Chambers (1988), a função de custo é uma estatística suficiente para a tecnologia. Portanto, a função de custo e seus conceitos relacionados (por exemplo, a função de lucro) provêem uma base natural para a investigação da tecnologia. A função de custo contém essencialmente a mesma informação que a função de produção contém. Qualquer conceito definido em termos das propriedades da função de produção tem uma definição dual em termos das propriedades da função de custo e vice-versa. Esta observação geral é conhecida como O princípio da Dualidade (Varian,1992). 
Segundo este autor, a função de produção sumariza a tecnologia da firma e a função de custo sumariza o seu aspecto econômico. Da teoria da dualidade sabe-se que, funções de produção e de custo são maneiras alternativas e exatas de caracterizar uma mesma tecnologia ${ }^{2}$ (Schmidt, 1985). De acordo com Chambers (1988), a especificação de uma função de custo bem comportada ${ }^{3}$ equivale à especificação de uma função de produção bem comportada. ${ }^{4}$

Tradicionalmente, na produção de frango de corte, as empresas avícolas têm procurado otimizar a produção através da obtenção de um maior ganho de peso, uma menor taxa de mortalidade e uma menor conversão alimentar. Neste caso, uma função de produção poderá provavelmente, representar o comportamento otimizador do ponto de vista físico. Contudo, uma abordagem de função de produção proporcionará apenas a medida de eficiência técnica da firma. Para medir a eficiência econômica, torna-se necessário representar o comportamento otimizador por funções-objetivo de custo ou de lucro.

Por definição, uma função de lucro é dada como:

$$
\begin{aligned}
\Pi(p, w) & =\max \{p f(x)-w . x\} & & x \geq 0 \\
& =\max \{p y-c(w, y)\} & & y \geq 0
\end{aligned}
$$

\footnotetext{
${ }^{2}$ A primeira aplicação empírica da teoria da dualidade foi realizada por Nerlove(1963), que estimou uma função de custo dual a uma função de produção Cobb-Douglas, baseado em uma amostra de 145 firmas produtoras de energia elétrica nos EUA (Greene,1980). Sob o enfoque de funções fronteira, as primeiras aplicações empíricas da dualidade neoclássica constam dos trabalhos de Forsund \& Jansen (1977), que estimaram uma função de custo fronteira determinística tipo Cobb-Douglas. Posteriormente Schmidt e Lovell (1979) estimaram também uma fronteira de custo estocástica tipo Cobb-Douglas.

${ }^{3}$ Uma função de custo bem comportada é uma função que satisfaz as propriedades de nãonegatividade, monotonicidade, concavidade, continuidade e homogeneidade de grau um nos preços dos fatores de produção e é não-decrescente no produto (Chambers, 1988).

${ }^{4}$ Uma função de produção bem comportada é aquela cujo conjunto de exigências de insumos é fechado, convexo e nã̃o é um conjunto vazio.Tal função satisfaz ainda as propriedades de monotonicidade e essencialidade fraca, é finita, não-negativa e de valor real para todo fator de produção finito e não-negativo (Chambers,1988).
} 
onde,

$\pi(p, w)$ representa a função de lucro da firma;

$\rho$ é o preço que os produtores tomam como dado;

w representa o preço dos insumos;

$f(x)$ representa a função de produção da firma;

$x$ representa a quantidade dos insumos;

y representa o produto da firma; e,

$c(w, y)$ representa a função de custo da firma.

A equivalência entre as duas representações na equação (4) pode ser tratada separando a função de lucro em dois estágios. 0 primeiro estágio, que pode ser intuitivamente concebido como de curto prazo, envolve maximizar lucro para um produto dado. O segundo estágio, que pode ser concebido como de longo prazo, trata da escolha do nivel de produto que maximiza o lucro. Quando o produto é dado, a receita também é dada e o lucro será maximizado por minimizar custo. Portanto, maximizar lucro com produto dado equivale a minimizar custo. Com base nestas considerações, uma funçãoobjetivo de custo pode ser utilizada satisfatoriamente neste trabalho para representar o comportamento otimizador de empresas avícolas. Pressupõe-se que tais empresas operam em mercados competitivos, onde o preço do produto e dos fatores são dados. Assim, a utilização de uma função de custo pode, então, ser compatível com o comportamento das empresas avícolas frente aos 
mercados de produto e de fatores. Os preços dos fatores e do produto são exógenos, enquanto as demandas por fatores e o custo total são endógenos. Segundo Greene (1980), para mercados competitivos, a pressuposição comportamental subjacente é que as firmas minimizam os custos de produção sujeitos ao produto, preços e função de produção.

A notação da função de custo considerada para representar o comportamento otimizador na produção de frangos de corte é aquela normalmente utilizada nos textos clássicos de microeconomia e economia da produção, ou seja:

$$
C=C\left(y, w_{1}, \ldots, w_{n}\right)
$$

A função de custo acima é o custo mínimo de produzir um dado produto $(y)$, durante um determinado período de tempo, para um vetor de preços dos fatores $w$.

\section{2- O modelo empírico}

Para a formulação do modelo empírico, levou-se em consideração o método a ser utilizado para obtenção da função de custo-fronteira, se econométrico ou de programação matemática e o tipo dos dados a serem analisados, de corte seccional (cross-section) ou dados longitudinais. As vantagens e desvantagens das abordagens econométrica e de programação matemática foram discutidas na revisão de literatura (capítulo II).

No presente trabalho foi escolhido o método econométrico de fronteiras estocásticas (Lovell \& Schmidt, 1988). Acredita-se que os desvios da fronteira de custo, lucro ou produção não devem ser atribuidos únicamente a ineficiência da firma, mas sim a ineficiência e a outros fatores fora do controle da firma. 
Os dados utilizados neste trabalho são dados longitudinais. Neste caso, a especificação de modelos econométricos para estimação de uma função de custo-fronteira e da eficiência econômica da firma, requer algumas pressuposições sobre o comportamento da eficiência. Considere-se o seguinte modelo geral para estimação de fronteiras de custo com dados longitudinais:

$$
C_{i t}=C\left(y_{i t}, w_{i t} \mid \beta\right) \exp \left[\varepsilon_{i t}\right]
$$

onde:

$C_{i t}$ representa o custo da i-ésima firma no t-ésimo periodo de tempo;

C(.) é a função de custo apresentada na equação (5);

$y_{i t} \in R^{n}+$ representa a produção da i-ésima firma no t-ésimo periodo de tempo;

$\boldsymbol{w}_{\text {it }} \in R^{m_{++}}$representa o vetor de preços dos insumos da i-ésima firma no t-ésimo periodo de tempo;

$\beta \in R^{k}$ representa o vetor de k parâmetros desconhecidos;

$\varepsilon_{i t}$ é um erro composto de efeitos aleatórios, ou seja, $\varepsilon_{i t}=v_{i t}+u_{i t}$;

$v_{i t}$ representam ruidos, erros de medição e outros fatores aleatórios para a i-ésima firma no t-ésimo período de tempo; e, 
$u_{i t}$ representam a ineficiência econômica da i-ésima firma no t-ésimo período de tempo.

Se os termos $u_{i t}$ são substituidos por $u_{i}$, o componente de eficiência é constante no tempo. Este é um caso limitante da equação (6). Um outro caso limitante da equação (6) trata-se da pressuposição de que para $t \neq$ t, $E\left(u_{i t} u_{i t^{\prime}}\right)=0$ para todo $i$ e $E\left(u_{i t} u_{j t}\right)=0$ para todo $i \neq j$. A especificação de um modelo com base nesta pressuposição é a mesma que aquela para dados cross-section, tornando-se irrelevante a natureza longitudinal dos dados. Um caso intermediário seria pressupor que para $t \neq t^{\prime}, E\left(u_{i t} u_{i t^{\prime}}\right)=\sigma_{t^{\prime}}$ para todo $i$ e $E\left(u_{i t} u_{j t}\right)=0$ para todo $i \neq j$. A pressuposição de que $E\left(u_{i t} u_{i t^{\prime}}\right)=\sigma_{t t^{\prime}}$, ou seja, que a covariância e variância sejam função do tempo (Pitt \& Lee,1981). Para Battese \& Coelii (1992), a ineficiência da firma pode aumentar, diminuir ou permanecer constante ao longo do tempo.

Com base nestas pressuposições, dois modelos econométricos foram especificados para estimação da função de custo-fronteira neste trabalho. O primeiro modelo (Modelo I) foi especificado com base na pressuposição de que para $t \neq t^{\prime}, E\left(u_{i t} u_{i t^{\prime}}\right)=0$ para todo $i$ e $E\left(u_{i t} u_{j t}\right)=0$ para todo $i \neq j$. Neste caso, as análisesão conduzidas como se os dados fossem do tipo crosssection. O segundo modelo (Modelo II) foi especificado com base na pressuposição de que a ineficiência é constante no tempo e variante entre firmas, isto é, $u_{i t}=u_{i t^{\prime}}=u_{i}, t \neq t^{\prime}, \forall i=1, \ldots, n$. Um terceiro modelo poderia ser especificado para estimação de fronteiras estocásticas, com base na pressuposição de que a ineficiência varia em função do tempo (Pitt \& Lee,1981 e Battese \& Coelli,1992). Contudo, existem ainda dificuldades quanto a implementação dos métodos de estimação (Pitt e Lee, 1981 e Greene,1993). Para estimação da eficiência técnica a partir de fronteiras de produção o método proposto por Battese e Coelii (1992) pode ser uma alternativa. 
As formulações para estimação da função de custo-fronteira com base no Modelo I e no Modelo II são dadas a seguir:

\section{Modelo I}

$$
C_{i}=C\left(y_{i}, w_{i} \mid \beta\right) \exp \left[\varepsilon_{i}\right]
$$

onde:

$C_{i}$ é o custo observado para a i-ésima observação;

C(.) é a função de custo apresentada na equação (5);

$y_{i} \in R^{n}+$ é a quantidade de produto para a $i$-ésima observação;

$\boldsymbol{w}_{i} \in R^{m}{ }_{++}$é o vetor de preços dos insumos para a $i$-ésima observação;

$\beta \in R^{k}$ é o vetor de $k$ parâmetros implicitamente definido em $C($.$) ;$

$\varepsilon_{i}$ é um erro composto de efeitos aleatórios, ou seja, $\varepsilon_{i}=v_{i}+u_{i}$;

$v_{i}$ representam ruidos, erros de medição e outros fatores aleatórios para a i-ésima firma; e,

$u_{i}$ representam a ineficiência econômica da $i$-ésima firma. 


\section{Modelo II}

$$
C_{i t}=C\left(y_{i t}, w_{i t} \mid \beta\right) \exp \left[\varepsilon_{i t}\right]
$$

onde:

$C_{\text {it }}$ representa o custo da i-ésima firma no t-ésimo periodo de observação;

C(.) é a função de custo apresentada na equação (5);

$y_{i t} \in R^{n}+$ representa a produção da i-ésima firma no t-ésimo periodo de observação;

$\boldsymbol{w}_{\text {it }} \in R^{m_{++}}$representa o vetor de preços dos insumos da i-ésima firma no t-ésimo periodo de observação;

$\beta \in R^{k} \quad$ representa o vetor de $k$ parâmetros desconhecidos;

$\varepsilon_{i t}$ é um erro composto de efeitos aleatórios, ou seja, $\varepsilon_{i t}=v_{i t}+u_{i}$;

$v_{i t}$ representam ruidos, erros de medição e outros fatores aleatórios para a i-ésima firma no t-ésimo período de tempo; e

$u_{i}$ representam a ineficiência econômica da i-ésima firma.

O modelo com erro composto foi independente e simultâneamente proposto por Aigner et alii (1977) e Meeusen \& Broeck (1977). A idéia por trás da formulação de um modelo com erro composto é que o componente $v_{i}$ é 
simétrico e estocástico, permitindo variação ao acaso da fronteira através das firmas, capturando erros de medição, ruídos estatísticos e choques aleatórios fora do controle da firma. Por outro lado, o componente $u_{i}$ é assimétrico e captura os efeitos de ineficiência relativos à fronteira estocástica (Forsund et alii, 1980). Aigner et alii (1977) sugeriram $u_{i}$ e $v_{i}$ mutuamente independentes, $v_{i}$, independente e identicamente distribuído como $N\left(0, \sigma_{v}{ }^{2}\right)$, e $u_{i}$ independente e identicamente distribuído como $\left|N\left(0, \sigma_{u}{ }_{u}\right)\right|$, ou seja:

$$
f(u)=\frac{\sqrt{2}}{\sigma_{u} \sqrt{\pi}} \exp \left[-\frac{1}{2}\left(\frac{u}{\sigma_{u}}\right)^{2}\right]
$$

onde,

$$
E[u]=\frac{\sqrt{2}}{\sqrt{\pi}} \sigma_{u}
$$

e

$$
\operatorname{Var}[u]=\left[\left(\frac{\pi}{2}\right)-1\right] \sigma_{u}^{2}
$$

Aigner et alii (1977) sugeriram também para $u_{i}$ uma distribuição exponencial, ou seja:

$f(u)=\theta e^{-\theta u}$ 
onde,

$$
E[u]=\frac{1}{\theta}
$$

e

$$
\operatorname{Var}[u]=\frac{1}{\theta^{2}}
$$

Stevenson (1980) sugeriu para $u_{i}$, uma distribuição normal truncada, com moda diferente de zero, equação (11), ao contrário de Aigner et alii (1977) que haviam sugerido uma moda igual a zero para as distribuições meio-normal e exponencial. Segundo Stevenson (1980), as especificações de Aigner et alii (1977) são baseadas numa pressuposição implícita de que a verossimilhança do comportamento ineficiente da firma decresce monotonicamente para niveis crescentes de ineficiência. Contudo, características tais como grau de treinamento educacional, inteligência, persuasão, etc. (fatores relacionados com a eficiência administrativa não são provavelmente distribuidos com uma função de densidade declinando monotonicamente sobre a população. Desde que os agentes econômicos são humanos ou instituições humanas, a possibilidade de uma moda diferente de zero para a função de densidade de $u_{i}$ seria uma pressuposição mais razoável. Tanto a distribuição meio-normal quanto a distribuição exponencial podem ser generalizadas para uma função de densidade de $u_{i}$ com moda diferente de zero, permitindo ainda que se teste para o caso especial de uma moda igual a zero. 


$$
f(u)=\frac{1}{\left(1-\Phi\left(-\frac{\mu}{\sigma_{u}}\right)\right) \sqrt{2 \pi} \sigma_{u}} \exp \left[-\frac{1}{2}\left(\frac{u-\mu}{\sigma_{u}}\right)^{2}\right]
$$

onde,

$$
\begin{aligned}
& E[u]=\mu+\sigma_{u}\left\{\frac{\phi\left(\frac{\mu}{\sigma_{u}}\right)}{\Phi\left(\frac{\mu}{\sigma_{u}}\right)}\right\} \\
& \operatorname{Var}[u]=\sigma_{u}{ }^{2}\left[1-\lambda_{u}\left(\frac{\mu}{\sigma_{u}}+\lambda_{u}\right)\right]
\end{aligned}
$$

$\mu$ é a moda da variável aleatória $u_{i}$

$$
\lambda_{u}=\frac{\phi\left(\frac{\mu}{\sigma_{u}}\right)}{\Phi\left(\frac{\mu}{\sigma_{u}}\right)}
$$

$\phi$ (.) e $\Phi$ (.) representam respectivamente a função de densidade de probabilidade e a função de distribuição para a variável aleatória normal padrão.

Neste trabalho, a distribuição normal truncada sugerida por Stevenson (1980), e as distribuições meio-normal e exponencial sugeridas por Aigner et alii(1977), foram consideradas para $u$, assim como as demais pressuposições sobre $u$ e $v$. Contudo, Greene (1993) tem chamado a atenção para o fato de que a pressuposição de uma distribuição normal truncada para 
estimação de parâmetros de funções de fronteiras estocásticas tem originado, embora nem sempre, problemas de convergência e estimativas sem sentido dos parâmetros.

Dadas as pressuposições de distribuição para $u$ (distribuições assimétricas), os parâmetros das funções de custo (modelos I e II) foram estimados por máxima verossimilhança. Segundo Greene (1980), quanto maior a assimetria da distribuição do erro, maior será o ganho em eficiência alcançado na utilização dos estimadores obtidos por máxima verossimilhança, sobre aqueles utilizando quadrados mínimos ordinários. Se os erros são simetricamente distribuídos, a distribuição aproxima-se da normalidade e o estimador resultante aproxima-se dos quadrados mínimos.

A função de densidade conjunta para $\varepsilon=v+u$ com uma especificação normal truncada para u (Stevenson,1980) é indicada na equação (12), e as funções de densidade de $\varepsilon=v+u$, com especificações meio-normal e exponencial para u, são dadas por Aigner et alii (1977).

$$
f(\varepsilon)=\frac{1}{\sigma} \phi\left(\frac{\varepsilon-\mu}{\sigma}\right)\left[1-\Phi\left(-\frac{\mu}{\sigma \lambda}-\frac{\varepsilon \lambda}{\sigma}\right)\right]\left[1-\Phi\left(-\frac{\mu}{\sigma_{u}}\right)\right]^{-1}
$$

onde,

$$
\begin{aligned}
& E[\varepsilon]=\frac{\mu a}{2}+\frac{\sigma_{u} a}{\sqrt{2 \pi}} \exp \left[-\frac{1}{2}\left(\frac{\mu}{\sigma_{u}}\right)^{2}\right] \\
& \operatorname{Var}[\varepsilon]=\mu^{2} \frac{a}{2}\left(1-\frac{a}{2}\right)+\sigma_{u}{ }^{2} \frac{a}{2}\left(\frac{\pi-a}{\pi}\right)+\sigma_{v}{ }^{2}
\end{aligned}
$$




$$
\begin{aligned}
& a=\left[1-\Phi\left(-\frac{\mu}{\sigma_{u}}\right)\right]^{-1} \\
& \sigma=\sqrt{{\sigma_{u}{ }^{2}+\sigma_{v}{ }^{2}}^{2}}
\end{aligned}
$$

e

$$
\lambda=\frac{\sigma_{u}}{\sigma_{v}}
$$

O parâmetro $\lambda$ é interpretado como um indicador da variabilidade relativa de $v$ e $u$ que distingue uma firma da outra. Se $\lambda^{2} \rightarrow 0$, isto significa dizer que 0 erro simétrico predomina na determinação de $\varepsilon$. Similarmente, se $\lambda^{2} \rightarrow \infty$, isto significa dizer que o erro assimétrico predomina na determinação de $\varepsilon$.

As funções de verossimilhanças nas suas formas logarítmicas (log-likelihood functions), utilizadas para estimar os parâmetros do Modelo I com especificação meio-normal, exponencial e normal-truncada para $u_{i}$, conforme Aigner et alii(1977) e Stevenson (1980) são dadas a seguir:

\section{Especificação Meio-Normal}

$$
\ln L\left(\beta, \lambda, \sigma^{2} \mid \varepsilon\right)=N \ln \frac{\sqrt{2}}{\sqrt{\pi}}+N \ln \frac{1}{\sigma}+\sum_{i=1}^{N} \ln \left[1-\Phi\left(\varepsilon_{i} \lambda \frac{1}{\sigma}\right)\right]-\frac{1}{2 \sigma^{2}} \sum_{i=1}^{N} \varepsilon_{i}{ }^{2}
$$

\section{Especificação Exponencial}

$$
\ln L\left(\beta, \theta, \sigma_{v} \mid \varepsilon\right)=N\left[\ln \theta+\frac{1}{2}\left(\theta \sigma_{v}\right)^{2}\right]+\sum_{i}\left[\ln \Phi\left(-\frac{\varepsilon_{i}}{\sigma_{v}}+\theta \sigma_{v}\right)+\theta \varepsilon_{i}\right]
$$


Especificação Normal-Truncada

$$
\begin{aligned}
\ln L\left(\beta, \lambda, \sigma^{2}, \mu \mid \varepsilon\right)= & -\frac{N}{2}\left(\ln \sigma^{2}+\ln 2 \pi\right)-\frac{1}{2 \sigma^{2}} \sum_{i=1}^{N}\left\{\left(\varepsilon_{i}-\mu\right)^{2}+\ln \left[\Phi\left(\frac{\mu}{\lambda}+\varepsilon_{i} \lambda\right)\right]\right\} \\
& -N \ln \left[\Phi\left(\frac{\mu}{\sigma}\right)\right]
\end{aligned}
$$

A forma logarítmica da função de verossimilhança utilizada para estimar os parâmetros do Modelo II com especificação normal-truncada para $u_{i}$ é dada por Greene (1993), conforme se segue:

Especificação Normal -Truncada

$$
\begin{aligned}
\ln L\left(\beta, \lambda, \sigma^{2}, \mu \mid \varepsilon\right)= & \sum_{i}\left\{-\frac{1}{2}\left[T_{i} \ln 2 \pi-\ln 2+T_{i} \ln \sigma_{v}{ }^{2}+\ln \left(1+\lambda T_{i}\right)-2 \ln \Phi\left(\frac{\mu}{\sigma_{v}}\right)\right]\right\} \\
& +\sum_{i}\left(-\frac{1}{2}\left\{\frac{-\lambda}{1+\lambda T_{i}}\left[\sum_{t} \frac{\left(\varepsilon_{i t}-\mu\right)}{\sigma_{v}}\right]^{2}+\sum_{t}\left[\frac{\left(\varepsilon_{i t}-\mu\right)}{\sigma_{u}}\right]^{2}\right\}\right) \\
& +\sum_{i} \ln \Phi\left\{\left(\frac{\lambda}{1+\lambda T_{i}}\right)^{\frac{1}{2}} \frac{1}{\sigma_{v}}\left[\sum_{t}\left(\varepsilon_{i t}-\mu\right)+T_{i} \mu\left(1-\frac{1}{\lambda}\right)\right]\right\}
\end{aligned}
$$

A forma logarítmica da função de verossimilhança para o modelo com especificação meio-normal pode ser produzida simplesmente por restringir $\mu=0$ na equação (16) de acordo com Greene(1993). Para cada firma individualmente as estimativas de $u_{i}$ foram obtidas (Modelos I e II) do erro composto $\varepsilon=v+u$, segundo Jondrow et alii (1982), considerando um modelo com especificação meio-normal (Greene, 1995). Para cada firma elou 
observação na amostra, a estimativa é o valor esperado de $u$ condicionado a $\varepsilon$, ou seja:

$$
E[u \mid \varepsilon]=\frac{\sigma \lambda}{\left(1+\lambda^{2}\right)}\left[\frac{\phi\left(\frac{\varepsilon \lambda}{\sigma}\right)}{1-\Phi\left(\frac{\varepsilon \lambda}{\sigma}\right)}-\frac{\varepsilon \lambda}{\sigma}\right]
$$

Para obter a contrapartida para o modelo normal truncado, segundo Greene (1995), muda-se $\varepsilon \lambda \sigma$ na equação (17) para:

$$
\frac{\varepsilon \lambda}{\sigma}+\frac{\dot{\mu}}{\sigma \lambda}
$$

Para o modelo exponencial, a estimativa de $u$, segundo Greene (1995), é dada por:

$$
E[u \mid \varepsilon]=z+\sigma_{v}\left[\frac{\phi\left(\frac{z}{\sigma_{v}}\right)}{\Phi\left(\frac{z}{\sigma_{v}}\right)}\right]
$$

onde:

$$
z=\varepsilon-\theta \sigma_{v}^{2}
$$


A estimativa de eficiência econômica para cada empresa foi calculada como:

$$
E E=\frac{C(y, w \mid \beta) \exp \{v\}}{C}
$$

onde,

$E E$ representa a eficiência econômica da i-ésima firma, $\mathrm{i}=1,2, \ldots, \mathbf{N}$;

$C(y, w \mid \beta)$ é a função de custo estimada para a i-ésima firma e descrita como nas equações 6,7 e 8;

$C$ é o custo observado para a i-ésima firma; e

$v$ é o componente simétrico do erro $\varepsilon$ obtido indiretamente após $u$ ser estimado pela equação 17 , ou seja, $v=\varepsilon-u$.

A descrição dos dados e das variáveis utilizadas nos modelos I e II, bem como a forma funcional escolhida para $C($.), são dadas a seguir.

\subsection{1- Dados}

Os dados utilizados neste trabalho referem-se a custos e produções mensais de frangos de corte de nove empresas avícolas, obtidos no periodo de janeiro de 1995 a abril de 1996. As empresas consideradas neste estudo representam aproximadamente $20 \%$ da produção nacional de frangos de corte. Contudo, apenas parte da sua produção e custo foi analisada. Estas 
empresas tem integrações no Sul e Sudeste do Brasil, mas apenas parte dos seus dados foram utilizados. Para algumas foram usados os dados do Sudeste, outras só os do Sul e outras uma parte do Sul e outra do Sudeste. Compõem também os dados da amostra empresas com uma única integração. Na tabela 3.1 pode ser observada, por empresa, a média mensal de produção de frangos de corte em toneladas.

Tabela 3.1 - Média mensal de produção de frangos de corte por empresa no período de janeiro de 1995 a abril de 1996

\begin{tabular}{ccc}
\hline \hline Empresa & No de obs & Produção(t) \\
\hline I & 11 & 691,84 \\
II & 16 & $4.718,14$ \\
III & 16 & $4.745,59$ \\
IV & 16 & $8.581,02$ \\
V & 16 & $2.462,56$ \\
VI & 16 & $4.199,15$ \\
VII & 12 & $1.982,19$ \\
VIII & 16 & $4.657,56$ \\
IX & 16 & $2.569,61$ \\
\hline \hline
\end{tabular}

Fonte: Planilhas de cụsto de produção das empresas amostradas

\subsection{2- Descrição das variáveis do modelo}

Custo: o custo C nos modelos I e II, é o custo variável da produção de frangos expresso em real, por empresa e por mês. Na produção de frangos de corte, $86,83 \%$ deste custo é representado pelo gasto com pintos 
de um dia e rações (Associação Paulista de Avicultura, 1995). Gastos com outros insumos são de difícil obtenção, uma vez que a maior parte das empresas estudadas são integrações avícolas. Gastos com gás, vacinas, desinfetantes e medicamentos, representam $2,5 \%$ dos custos variáveis e são computados. Contudo, o são apenas em valores monetários, sendo difícil a recuperação das quantidades utilizadas. Os demais gastos, como por exemplo, despesas com mão-de-obra, cama de aviário, energia elétrica, Funrural, etc. representando 10,67\% do custo variável (Associação Paulista de Avicultura, 1995), são considerados pelas integrações como a contrapartida do produtor, não sendo, portanto, registrados.

Desse modo, apenas os gastos com pintos de um dia e com rações foram considerados como componentes do custo variável, neste trabalho.

Produto: a quantidade de produto $Y$ por empresa, foi representado pelo peso ao abate do lote de frangos em toneladas / mês.

Preços dos insumos: os preços $\mathbf{W}$ dos insumos foram aqueles correspondentes apenas a pintos de um dia (preço por 1000 unidades) e ração (preço por tonelada), dados os motivos explicados acima. Todos os preços foram expressos em reais, e deflacionados segundo o IGP-FGV (Base: Abril / $96=1,00)$.

Quantidade dos insumos: Foram consideradas as quantidades $\mathbf{X}$ de pintos de um dia (1000 unidades) e de ração (toneladas) utilizadas no processo de produção das empresas no mês. ,

A estatística descritiva das variáveis selecionadas para análise constam da tabela 3.2. 
Tabela 3.2 - Estatística descritiva das variáveis selecionadas para análise

\begin{tabular}{lccccc}
\hline \hline \multicolumn{1}{c}{ Variável } & No de obs $^{\circ}$ & Mínimo & Médio & Máximo & D.Padrão \\
\hline \hline CUSTO & 135 & 385,80 & 516,47 & 643,70 & 49,94 \\
PRODUTO & 135 & 484,90 & 4017,30 & 9489 & 2175,90 \\
PREÇO PINTO & 135 & 173,30 & 219,59 & 305,80 & 27,762 \\
PREÇO RAÇÃO & 135 & 143,80 & 200,76 & 263 & 24,727 \\
QUANT. PINTO & 135 & 241,30 & 1979,90 & 5003 & 1150,10 \\
QUANT. RAÇÃO & 135 & 1004 & 8197,30 & 18490 & 4397,2 \\
\hline \hline
\end{tabular}

Fonte: Planilhas de custo de produção das empresas amostradas

\subsection{3 - Forma funcional adotada para o modelo}

Os poucos estudos realizados para estimar a eficiência econômica de empresas agrícolas utilizaram uma função de produção do tipo Cobb-Douglas e sua função de custo derivada analiticamente (Taylor et alii,1986, Bravo-Ureta e Rieger, 1991 e Bravo-Ureta e Eveson, 1992). Kumbakar $(1989,1994)$ utilizou funções de produção do tipo Cobb-Douglas e translog e as condições de primeira ordem para maximização de lucro. Kalirajan (1990) utilizou uma função de produção translog e as condições de primeira ordem para maximização de lucros e Ali \& Flinn (1989) trabalharam com uma função de lucro do tipo translog.

As críticas relacionadas à utilização de funções de produção do tipo Cobb-Douglas nos estudos de eficiência econômica dizem respeito, principalmente, a multicolinearidade existente entre os fatores de produção. Com relação a funções de custo do tipo Cobb-Douglas derivadas 
analíticamente, as restrições impostas aos parâmetros de escala e de substituição são os maiores problemas.

Formas funcionais do tipo translog têm sido recomendadas para estudos de eficiência econômica por serem flexíveis, não impondo restrições sobre as possibilidades de substituição entre os fatores de produção nem sobre as propriedades de escala (Christensen \& Greene, 1976). Contudo, existem desvantagens na utilização de formas funcionais do tipo translog, sendo a principal a sua incapacidade de manipular variáveis explanatórias com valor zero (Shirota, 1995).

Outras formas funcionais têm sido indicadas na literatura para estimação de funções de lucro e de custo. As suas vantagens e desvantagens podem ser apreciadas em Baumol et alii (1988).

Para o modelo de produção considerado neste trabalho, ou seja, um modelo com um produto e dois insumos, a forma funcional escolhida para a função de custo foi a trans $\log ^{5}$ (equação 21). Além de flexível, a forma funcional translog tem como casos especiais outras formas funcionais, desde que sejam impostas restrições adicionais sobre os parâmetros da função. Isto faz desta forma funcional uma forma atraente aos estudos de economia da produção. Por exemplo, para que a função translog seja homotética é necessário e suficiente que $\beta_{i y}=0 \forall i=1, \ldots n$. Já a homogeneidade de grau constante no produto ocorre se, em adição a esta restrição de homoteticidade, $\beta_{y y}=0$; neste caso, o grau de homogeneidade é igual a $\frac{1}{\beta_{y}}$. Retornos constantes à escala da função de produção dual ocorrem quando, em adição às restrições de homoteticidade e homogeneidade acima, $\beta_{y}=1$. Por último, a função translog de custo pode se reduzir a uma função de custo Cobb-Douglas com retornos constantes à

\footnotetext{
${ }^{5}$ Dos estudos sobre eficiência econômica na agricultura, apenas Parik e Shah(1994) utilizaram uma função de custo transiog para estimar fronteiras. Os demais trabalhos utilizaram funções de produção e de lucro do tipo translog.
} 
escala, quando em adição a todas as restrições impostas acima, cada um dos $\beta_{i j}=0, \forall \mathrm{i}, \mathrm{j}=1, \ldots, \mathrm{n}$ (Berndt, 1990).

Desse modo, a forma funcional translog que especifica o modelo empírico neste trabalho tem a seguinte forma geral:

$$
\begin{aligned}
\ln C & =\beta_{0}+\sum_{i=1}^{n} \beta_{i} \ln w_{i}+\frac{1}{2} \sum_{i=1}^{n} \sum_{j=1}^{n} \beta_{i j} \ln w_{i} \ln w_{j}+\beta_{y} \ln y \\
& +\frac{1}{2} \beta_{y y}(\ln y)^{2}+\sum_{i=1}^{n} \beta_{i y} \ln w_{i} \ln y
\end{aligned}
$$

onde:

C, ye w são, respectivamente, o custo, o produto e o vetor de preços dos fatores de produção; e

os $\beta$ são os parâmetros da função de custo translog

A condição de simetria para a função de custo translog, é obtida pelas restrições impostas aos parâmetros, conforme o teorema de Young, ou seja:

$$
\beta_{i j}=\beta_{j i}
$$

Para corresponder a uma função de produção bem comportada, entre outras coisas, a função de custo deve ser homogênea de grau um nos preços, dado $y$, ou seja, para um nível fixo de produto, o custo total deve aumentar proporcionalmente ao aumento proporcional dos preços dos fatores. Isto implica as seguintes relações entre os parâmetros:

$$
\sum_{i=1}^{n} \beta_{i}=1 \quad \sum_{i=1}^{n} \beta_{i j}=\sum_{i=1}^{n} \beta_{i y}=0
$$




\section{RESULTADOS E DISCUSSÃO}

\section{1- Estimação da função de custo fronteira}

\subsection{1 - Modelo I}

A função de custo-fronteira para as empresas avícolas, empregando pintos de um dia e ração, para produção de frangos de corte, equação (24), foi estimada inicialmente com base nas pressuposições do modelo I, conforme constam da metodologia. Adotou-se a forma flexível translog para a função de custo, com distribuição normal truncada para $u_{i} \mathrm{e}$ restrição de homogeneidade linear nos preços dos fatores. A restrição de homogeneidade linear nos preços dos fatores foi imposta, normalizando-se o custo $(C)$ e o preço do pinto de um dia $\left(w_{1}\right)$ pelo preço da ração $\left(w_{2}\right)$, ou seja:

$$
\begin{aligned}
\ln \left(\frac{C}{w_{2}}\right) & =\beta_{0}+\beta_{1} \ln y+\frac{1}{2} \cdot \beta_{11}(\ln y)^{2}+\beta_{2} \ln \left(\frac{w_{1}}{w_{2}}\right)+\frac{1}{2} \cdot \beta_{22}\left[\ln \left(\frac{w_{1}}{w_{2}}\right)\right]^{2} \\
& +\beta_{12} \ln y \ln \left(\frac{w_{1}}{w_{2}}\right)+\varepsilon
\end{aligned}
$$

onde:

In é o logaritmo neperiano;

$\left(C / w_{2}\right)$ é o custo normalizado;

y é a quantidade de frangos produzida em toneladas; 
$\left(w_{1} / w_{2}\right)$ é o preço do pinto de um dia normalizado;

Os $\beta$ são os parâmetros da função; e

$\varepsilon$ é o erro composto de efeitos aleatórios, ou seja, $\varepsilon=v+|u|$, conforme descrito para o Modelo I na metodologia.

As estimativas por máxima verossimilhança dos parâmetros da função de custo-fronteira acima constam da tabela 4.1. O teste-z assintótico dos parâmetros estimados sugere outra forma funcional que não a translog, assim como rejeita a hipótese de uma distribuição normal truncada para $u_{i}$. As estimativas dos parâmetros $\beta_{11} / 2, \beta_{22} / 2, \beta_{12}$ e $\mu$ não foram estatísticamente diferentes de zero ao nivel de $5 \%$ de probabilidade. Apenas as estimativas dos parâmetros $\beta_{1}$ e $\beta_{2}$ foram estatísticamente diferentes de zero, sugerindo para os dados uma forma funcional log-linear. Uma moda $\mu=0$ sugere para $u_{i}$ uma distribuição meio-normal.

Dados os resultados da tabela 4.1 , considerou-se para $u_{i}$ no Modelo I uma distribuição meio-normal. Uma função de custo fronteira loglinear (tipo Cobb-Douglas), com homogeneidade linear imposta sobre os preços dos fatores, equação (25), foi ajustada e os parâmetros estimados por máxima verossimilhança (tabela 4.2 ).

$$
\ln \left(\frac{C}{w_{2}}\right)=\beta_{0}+\beta_{1} \ln y+\beta_{2} \ln \left(\frac{w_{1}}{w_{2}}\right)+\varepsilon
$$

Todos os parâmetros e variáveis da forma funcional dada na equação (25) são os mesmos descritos para a forma funcional translog, levando-se obviamente em consideração, as restrições impostas à forma 
translog para obtenção de uma forma funcional do tipo Cobb-Douglas, de acordo com Berndt (1991), e apresentadas no item 3.2.3 da metodologia.

Tabela 4.1. Coeficientes estimados para a função de custo fronteira transloga com especificação normal truncada (Modelo I).

\begin{tabular}{|c|c|c|c|c|c|}
\hline Parâmetros & Variável & Estimativa & Erro-padrão & $t=b / e . p$ & $P>|t|$ \\
\hline$\beta_{0}$ & Constante & 0,43451 & 0,35599 & 1,221 & 0,22225 \\
\hline$\beta_{1}$ & Iny & 1,1050 & 0,08663 & 12,363 & 0,00000 \\
\hline$\beta_{2}$ & $\ln \left(w_{1} / w_{2}\right)$ & 0,43278 & 0,19260 & 2,486 & 0,02464 \\
\hline$\left(\beta_{11}\right) / 2$ & $(\ln y)^{2}$ & $-0,01155$ & 0,01054 & $-1,243$ & 0,27325 \\
\hline$\left(\beta_{22}\right) / 2$ & {$\left[\ln \left(w_{1} / w_{2}\right)\right]^{2}$} & 0,03494 & 0,11837 & 1,603 & 0,76780 \\
\hline$\beta_{12}$ & $\ln y \ln \left(w_{1} / w_{2}\right)$ & $-0,02136$ & 0,02421 & $-1,062$ & 0,37767 \\
\hline$\mu$ & & $-0,62255$ & 2,6480 & $-0,235$ & 0,81413 \\
\hline$\lambda$ & & 2,4431 & 1,0759 & 2,271 & 0,02316 \\
\hline$\sigma$ & & 0,03713 & 0,01880 & 1,975 & 0,04828 \\
\hline$\sigma_{u}^{2}$ & & 0,00118 & & & \\
\hline$\sigma_{v}^{2}$ & & 0,00020 & & & \\
\hline $\mathrm{LFV}^{\mathrm{b}}$ & & 328,2486 & & & \\
\hline
\end{tabular}


Tabela 4.2 - Coeficientes estimados para a função de custo fronteira log-linear, tipo Cobb-Douglas, com especificação meio-normal (Modelo I).

\begin{tabular}{llllll}
\hline \hline Parâmetros & Variáveis & Estimativas & Erro-padrão & $t=b / e . p$ & $P>|t|$ \\
\hline \hline$\beta_{0}$ & Constante & 0,84495 & 0,026692 & 31,665 & 0,00000 \\
$\beta_{1}$ & Iny & 1,0072 & 0,0032247 & 312,342 & 0,00000 \\
$\beta_{2}$ & $\ln \left(w_{1} / w_{2}\right)$ & 0,25578 & 0,012976 & 19,712 & 0,00000 \\
$\lambda$ & & 1,8462 & 0,47567 & 3,881 & 0,00010 \\
$\sigma$ & & 0,03051 & 0,0029478 & 10,352 & 0,00000 \\
$\sigma_{v}{ }^{2}$ & & 0,00021 & & & \\
$\sigma_{u}{ }^{2}$ & & 0,00072 & & & \\
LFV & 327,4292 & & & \\
\hline \hline
\end{tabular}

Fonte: Dados de pesquisa.

Da tabela 4.2 pode-se constatar que todas as estimativas dos parâmetros foram altamente significativas.

A função de custo fronteira estimada atende aos pressupostos teóricos considerados essenciais a uma função de custo bem comportada. A função estimada é não-decrescente nos preços dos fatores, o que reflete custo marginal positivo. Para uma função log-linear do tipo Cobb-Douglas, tal pressuposição pode ser verificada como a seguir:

$$
\frac{\partial C(.)}{\partial y_{i}}=\frac{\partial \ln C(.)}{\partial \ln y_{i}} \cdot \frac{C(\cdot)}{y_{i}}=\beta_{y} \cdot \frac{C(\cdot)}{y_{i}}
$$


Dado que $C($.$) e y_{i}$ são positivos nos valores, o sinal do custo marginal dependerá do sinal do parametro $\beta_{1}$, que na função estimada é positivo.

A pressuposição de que uma função de custo bem comportada seja côncava nos preços dos fatores também é atendida. Para que uma função de custo seja côncava nos preços dos fatores de produção, a matriz de derivadas segunda (hessiano) tem que ser negativa semi-definida. Uma matriz negativa semi-definida possui os determinantes menores principais com sinal $(-1)^{k}$, onde $\mathrm{k}$ é a ordem do menor principal (Chiang,1984). Esta condição pode ser verificada para a função acima, pelo sinal do parâmetro $\beta_{i}$ estimado, ou seja:

$$
\frac{\partial C(\cdot)}{\partial w_{i}}=\frac{\partial \ln C(\cdot)}{\partial \ln w_{i}} \cdot \frac{C(\cdot)}{w_{i}}=\beta_{i} \cdot \frac{C(\cdot)}{w_{i}}
$$

portanto,

$$
\frac{\partial^{2} C(\cdot)}{\partial w^{2}}=-\beta_{i} \cdot \frac{C(\cdot)}{w_{i}^{2}}
$$

Desde que $C($.$) e w=\left[w_{1}, w_{2}, \ldots, w_{3}\right]$ são sempre positivos, o sinal da equação (28) depende do sinal de $\beta_{i}$. Neste trabalho, o parâmetro $\beta_{2}$ estimado na função log-linear é igual a 0,25578 e $\beta_{3}=1-\beta_{2}$. Assim, a condição acima é satisfeita para ambos os parâmetros e a função log-linear de custofronteira é realmente côncava nos preços dos fatores. 
Um importante resultado da tabela 4.2 é a estimativa do parâmetro $\lambda$. O valor de $\lambda=1,8462$ implica que o erro assimétrico $u$ predomina sobre o erro simétrico $v$. A var[u] responde por $66,29 \%$ da variância total. Neste caso, a discrepância entre o custo observado e a fronteira de custo é primariamente devido a ineficiência.

Dado que o modelo é parametrizado em termos de $\lambda=\sigma_{u} / \sigma_{v}$ e $\sigma^{2}=\sigma_{u}^{2}+\sigma_{v}^{2}$, pode-se considerar a razão das variâncias $\sigma_{u}^{2} / \sigma^{2}$ como um indicador útil da influência do componente de ineficiência na variância total. Contudo, a variância da variável aleatória $u$ é [ ( $\pi / 2)-1] \sigma^{2}{ }_{u}$, não $\sigma^{2}{ }_{u}$. Assim, na decomposição da variância total em 2 componentes, a contribuição de u será [ ( $\pi / 2)-1] \sigma^{2}{ }_{u} / \sigma^{2}{ }_{v}+[(\pi / 2)-1] \sigma_{u}^{2}$ (Greene, 1993).

As estimativas dos parâmetros da função de custo log-linear tipo Cobb-Douglas, equação (25), utilizando uma distribuição exponencial para $u$ foram também obtidas e estão indicadas na tabela 4.3. Pode-se constatar que as estimativas dos parâmetros por máxima verossimilhança foram todas altamente significativas. $\dot{E}$ interessante notar que as diferenças entre as estimativas dos parâmetros $\beta_{0}, \beta_{1}$ e $\beta_{2}$ dos modelos com especificação meio-normal (tabela 4.2) e exponencial (tabela 4.3) foram muito pequenas, o que sugere certa consistência das estimativas. Ao contrário do modelo com distribuição meio-normal (MIDMN), no modelo com distribuição exponencial (MIDEX) a discrepância entre o custo observado e a fronteira de custo é primariamente devido ao componente simétrico do erro. No modelo exponencial o componente devido a ineficiência responde por $44,68 \%$ da variância total.

A exemplo do MIDMN, no MIDEX todos os pressupostos a uma função de custo bem comportada foram atendidos 
Tabela 4.3 - Coeficientes estimados para a função de custo fronteira log-linear, tipo Cobb-Douglas, com especificação exponencial (Modelo I).

\begin{tabular}{llllll}
\hline \hline Parâmetros & Variáveis & Estimativas & Erro-padrão & $t=b / e . p$ & $P>|t|$ \\
\hline \hline$\beta_{0}$ & Constante & 0,85158 & 0,0257 & 33,971 & 0,0000 \\
$\beta_{1}$ & Iny & 1,0072 & 0,00301 & 334,276 & 0,0000 \\
$\beta_{2}$ & $\ln \left(w_{1} / w_{2}\right)$ & 0,25771 & 0,01208 & 21,336 & 0,0000 \\
$\theta$ & & 68,847 & 14,35 & 4,798 & 0,0000 \\
$\sigma_{u}{ }^{2}$ & & 0,00021 & & & \\
$\sigma_{v}{ }^{2}$ & & 0,00026 & & & \\
$\sigma^{2}$ & & 0,00047 & & & \\
LFV & 328,67 & & & \\
\hline \hline
\end{tabular}

Fonte:Dados de pesquisa.

\subsection{2- Modelo II}

Considerando a natureza longitudinal dos dados neste trabalho, uma função de custo-fronteira log-linear tipo Cobb-Douglas foi estimada com base nas pressuposições do modelo II conforme consta da metodologia. Neste caso, o modelo de efeitos aleatórios com distribuição meio-normal para $u$, segundo Greene(1995), foi empregado na obtenção das estimativas dos parâmetros da função de custo-fronteira, equação(29). Uma função de custo translog também foi utilizada como forma funcional para a função de custo do Modelo II. Contudo, a exemplo do Modelo I, as estimativas dos parâmetros $\beta_{1} / 2, \beta_{22} / 2, \beta_{12}$ e $\mu$ não foram estatísticamente diferentes de zero ao nível de $5 \%$ de probabilidade. A restrição de homogeneidade linear também foi mantida para a função de custo do Modelo II, como na função de custo do Modelo I. 


$$
\ln C_{i t}=\beta_{0}+\beta_{1} \ln y_{i t}+\beta_{2} \ln w_{i t}+\varepsilon_{i t}
$$

onde:

$C_{i t}$ é o custo normalizado para a $i$-ésima empresa, $i=1,2, \ldots, N$, no $t$ ésimo período de observação, $t=1,2, \ldots, \mathrm{T}$;

$y_{i t}$ é o produto observado para a i-ésima empresa no t-ésimo período de observação;

$w_{i t}$ é o preço do insumo normalizado para a i-ésima empresa no t-ésimo período de observação;

Os $\beta$ são os parâmetros da função log-linear; e

$\varepsilon_{i t}$ é o erro composto, ou seja, $\varepsilon_{i t}=v_{i t}+u_{i}$, conforme descrito no Modelo II.

Os $u_{i}$ são iid $\left|N\left(0, \sigma_{u}^{2}\right)\right|$; e

Os $v_{i t}$ são iid $N\left(0, \sigma_{v}^{2}\right)$

As estimativas por máxima verossimilhança dos parâmetros da função de custo-fronteira com base nas pressuposições do Modelo II constam da tabela 4.4. 
Tabela 4.4 - Coeficientes estimados para a função de custo-fronteira log-linear, tipo Cobb-Douglas, com especificação meio-normal (Modelo II).

\begin{tabular}{llllll}
\hline \hline Parâmetros & Variáveis & Estimativas & Erro-padrão & $\mathrm{t}=$ b/e.p & $\mathrm{P}>|\mathrm{t}|$ \\
\hline \hline$\beta_{0}$ & Constante & 0,9517 & 0,05997 & 15,870 & 0,00000 \\
$\beta_{1}$ & Iny & 0,99363 & 0,00752 & 132,096 & 0,00000 \\
$\beta_{2}$ & $\ln \left(w_{1} / W_{2}\right)$ & 0,2029 & 0,01379 & 14,710 & 0,00000 \\
$\lambda$ & & 5,3802 & 4,529 & 1,188 & 0,23484 \\
$\sigma_{\mathrm{v}}{ }^{2}$ & & 0,00022 & 0,00003 & 6,556 & 0,0000 \\
$\sigma_{\mathrm{u}}{ }^{2}$ & & & & \\
LFV & 0,00120 & & & \\
\hline
\end{tabular}

Fonte:Dados de pesquisa

Todas as estimativas dos parâmetros foram altamente significativas, com exceção de $\lambda$, conforme indicado pelo teste-t. Contudo, 0 valor de $\lambda=5,3802$ implica que o erro assimétrico $u$ predomina sobre o erro simétrico $v$. Neste caso, a discrepância entre o custo observado e a fronteira de custo pode ser interpretada como primariamente devido a ineficiência. No MIIEA a variância de $u$ responde por $75,69 \%$ da variância total.

Uma análise das tabelas 4.2, 4.3 e 4.4 evidencia que os errospadrão das estimativas dos parâmetros do MIDMN e MIDEX foram um pouco menores do que aqueles obtidos pelo modelo de efeitos aleatórios (Modelo II) para dados longitudinais (MIIEA). Isto revela que o MIDMN e o MIDEX proporcionaram estimativas mais eficientes dos parâmetros da função de custo estimada. Estimativas de erros-padrão mais elevadas para os parâmetros estimados do Modelo II podem ser decorrentes do pequeno número de empresas disponíveis para estudo neste trabalho. Caso um maior número de 
empresas fosse considerado poder-se-ia esperar estimativas dos parâmetros com menores erros-padrão. Isto poderia implicar numa estimativa de $\lambda$ estatísticamente diferente de zero pelo teste-t, uma vez que no MIIEA a variância de $u$ responde por $75,69 \%$ da variância total, conforme descrito acima.

A exemplo do MIDMN e do MIDEX, no MIIEA todos os pressupostos a uma função de custo bem comportada foram atendidos.

\section{2- Eficiência econômica na produção de frango de corte}

As estimativas de eficiência econômica obtidas a partir do Modelo I com especificação meio-normal e exponencial para $u_{i}$ juntamente com as estimativas obtidas do Modelo II com especificação meio-normal constam da tabela 4.5 .

Tabela 4.5 - Estatística descritiva das estimativas de eficiência econômica obtidas com base no MIDMN, MIDEX e MIIEA.

\begin{tabular}{cccccccc}
\hline \hline Modelo & Obs & Média & D.P & C.V & Mínimo & Máximo & Assimetria \\
\hline \hline MIDMN & 135 & 0,9790 & 0,0122 & 1,2526 & 0,9266 & 0,9946 & $-1,75$ \\
MIDEX & 135 & 0,9856 & 0,0107 & 1,0901 & 0,9285 & 0,9956 & $-3,10$ \\
MIIEA & 135 & 0,9712 & 0,0212 & 2,1785 & 0,9049 & 1,0000 & $-0,63$ \\
\hline \hline
\end{tabular}

Fonte:Dados de pesquisa. 
O nivel de eficiência econômica (EE) na utilização dos insumos para produção de frango de corte foi bastante elevado tanto no Modelo I (MIDMN e MIDEX) como no Modelo II (MIIEA). Em média, as empresas produtoras de frangos analisadas apresentaram uma eficiência na utilização dos insumos da ordem de 97,90\% no modelo I com especificação meio-normal e de $98,56 \%$ no modelo I com especificação exponencial. Isto significa que incorreram, no periodo analisado, em perdas no produto da ordem de 2,10\% e $1,44 \%$ com base no MIDMN e no MIDEX, respectivamente, devido a ineficiência econômica(custo). A ineficiência econômica média estimada com base no MIIEA foi da ordem de 2,88\%, maior do que no MIDMN e no MIDEX. $\mathrm{Na}$ tabela 4.5 pode-se observar também que as distribuições das estimativas de eficiência, obtidas com base no MIDMN, MIDEX e MIIEA, são todas assimétricas à esquerda como esperado, o que pode ser confirmado pelos valores negativos das medidas de assimetria.

As correlações entre as estimativas de eficiência econômica obtidas do MIDMN, MIDEX e MIIEA constam da tabela 4.6. Pode-se nela constatar uma maior correlação entre as estimativas de eficiência obtidas pelo MIDMN e MIDEX, do que entre estas e as estimativas obtidas pelo MIIEA.

Tabela 4.6 - Correlações entre estimativas de eficiência econômica (EE) obtidas com base no MIDMN, MIDEX e MIIEA.

\begin{tabular}{cccc}
\hline \hline Variáveis & EE (MIDEX) & EE (MIIEA) & EE (MIDMN) \\
\hline \hline EE (MIDEX) & 1,0000 & & \\
EE (MIIEA) & 0,8292 & 1,0000 & 1,0000 \\
EE (MIDMN) & 0,9742 & 0,8903 & 1,000 \\
\hline
\end{tabular}

Fonte:Dados de pesquisa. 
A ausência na literatura de estudos sobre eficiência econômica na produção de frango de corte, infelizmente não permite comparar os resultados obtidos neste trabalho. Entretanto, na agricultura, de um modo geral, os resultados têm sido bastante variáveis conforme se constatou na revisão de literatura (capítulo 2).

Neste trabalho, algumas estimativas de eficiência econômica obtidas através do MIIEA foram maiores do que um. De acordo com Shirota (1995), o procedimento de estimação utilizado permite algumas observações se posicionarem abaixo da fronteira de custo. Isto ocorre quando o efeito do erro composto é negativo e sobrepõe-se ao efeito do erro assimétrico atribuido à ineficiência custo. $\mathrm{O}$ autor acima ponderou que, embora do ponto de vista teórico tal fato não seja concebivel, pode ser perfeitamente aceitável em análises empíricas com modelos de erro composto. Assim, os valores de eficiência maiores do que um foram ajustados para um, o que se justifica, uma vez que a fonte desta inconsistência é gerada por empresas operando muito próximas ou na fronteira de custo.

As médias das estimativas de eficiência econômica com base no MIDMN, MIDEX e MIIEA por empresas constam das tabelas 4.7, 4.8, e 4.9. As figuras 4.1, 4.2 e 4.3, permitem adicionalmente, visualizar a posição das empresas com relação a eficiência econômica.

As estimativas de eficiência econômica foram obtidas utilizandose a equação 20 , para o MIDMN, MIDEX e MIIEA, conforme consta da metodologia (capítulo 3). 
Tabela 4.7 - Estimativa da eficiência econômica média (EE) por empresa com base no Modelo I com especificação meio-normal (MIDMN).

\begin{tabular}{cccc}
\hline \hline Empresas & No de obs $^{\circ}$ & EE & Classificação \\
\hline \hline IX & 16 & 0,9893 & 1 \\
IV & 16 & 0,9857 & 2 \\
VI & 16 & 0,9831 & 3 \\
III & 16 & 0,9813 & 4 \\
V & 16 & 0,9812 & 5 \\
VII & 12 & 0,9806 & 6 \\
I & 11 & 0,9790 & 7 \\
VIII & 16 & 0,9742 & 8 \\
II & 16 & 0,9574 & 9 \\
\hline \hline
\end{tabular}

Fonte:Dados de pesquisa

Tabela 4.8 - Estimativa da eficiência econômica (EE) média por empresa com base no Modelo I com especificação exponencial (MIDEX).

\begin{tabular}{cccc}
\hline \hline Empresas & No de obs $^{\circ}$ & EE & Classificação \\
\hline \hline IX & 16 & 0,9927 & 1 \\
IV & 16 & 0,9908 & 2 \\
VI & 16 & 0,9890 & 3 \\
III & 16 & 0,9878 & 4 \\
VII & 12 & 0,9878 & 5 \\
V & 16 & 0,9877 & 6 \\
I & 11 & 0,9864 & 7 \\
VIII & 16 & 0,9831 & 8 \\
II & 16 & 0,9663 & 9 \\
\hline
\end{tabular}

Fonte: Dados de pesquisa. 
Tabela 4.9 - Estimativa da eficiência econômica (EE) média por empresa com base no Modelo II de efeitos aleatórios (MIIEA).

\begin{tabular}{cccc}
\hline \hline Empresas & N $^{\mathbf{2}}$ de obs & EE & Classificação \\
\hline \hline IX & 16 & 0,9960 & 1 \\
V & 16 & 0,9828 & 2 \\
VI & 16 & 0,9814 & 3 \\
VII & 12 & 0,9772 & 4 \\
III & 16 & 0,9754 & 5 \\
I & 11 & 0,9730 & 6 \\
IV & 16 & 0,9666 & 7 \\
VIII & 16 & 0,9540 & 8 \\
II & 16 & 0,9364 & 9 \\
\hline
\end{tabular}

Fonte: Dados de pesquisa.

Pode ser observado nas tabelas 4.7 e 4.8 uma pequena alteração no ranking das empresas $\mathrm{V}$ e VII com base nas estimativas de EE pelo MIDMN e MIDEX. Uma maior alteração no ranking das firmas se deu nas estimativas de eficiência obtidas pelo MIIEA (tabela 4.9), em relação a aquelas obtidas pelo MIDMN e MIDEX. Pelo MIDEX um maior nível de eficiência foi detectado em relação ao MIDMN, contudo tais diferenças são muito pequenas. Greene (1993) também obteve estimativas de ineficiência custo mais elevadas no modelo com especificação meio-normal, quando comparadas ao modelo com especificação exponencial. Contudo, segundo o autor acima, não está disponível qualquer teste de especificação capaz de indicar a superioridade de um ou outro modelo. 


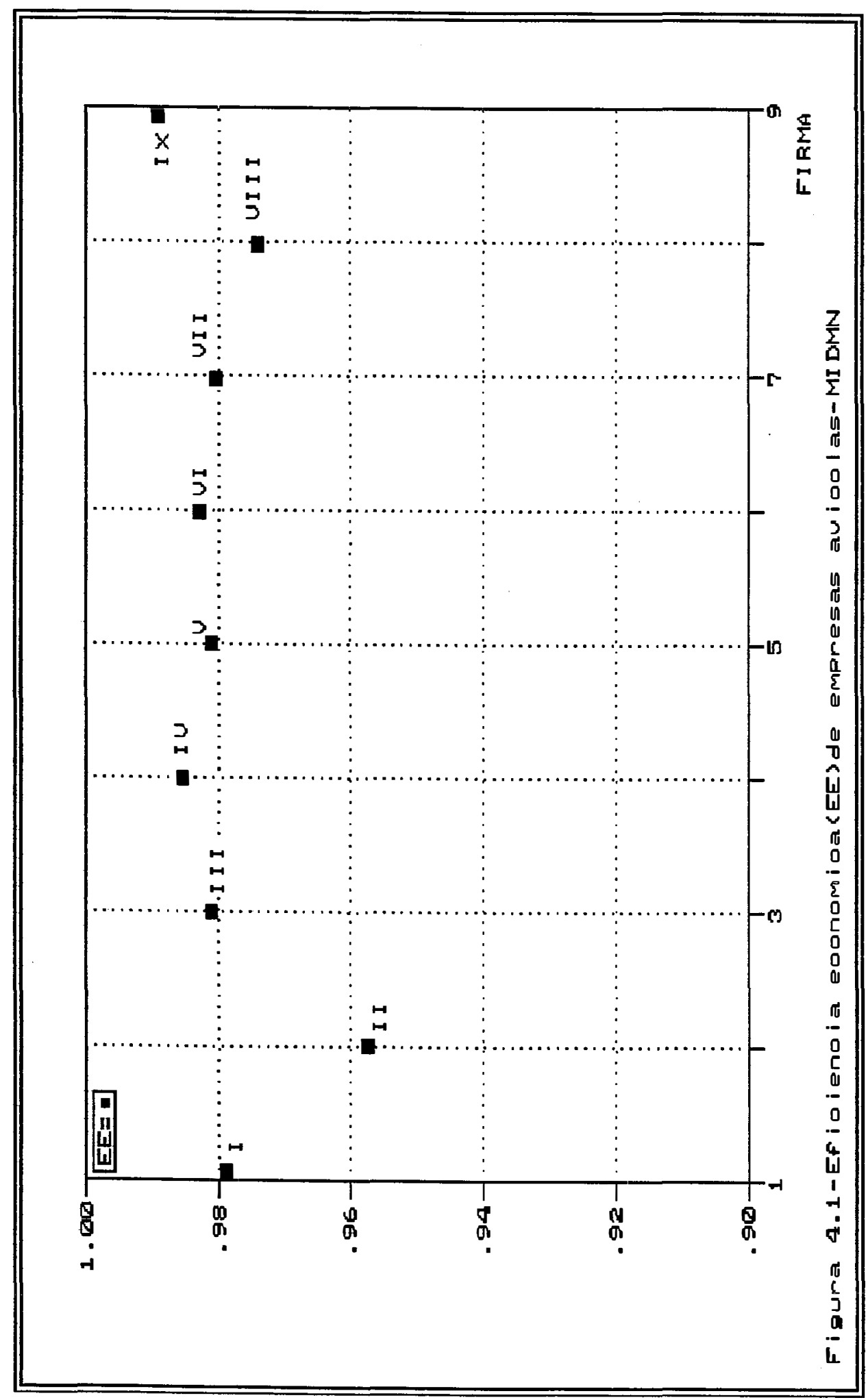




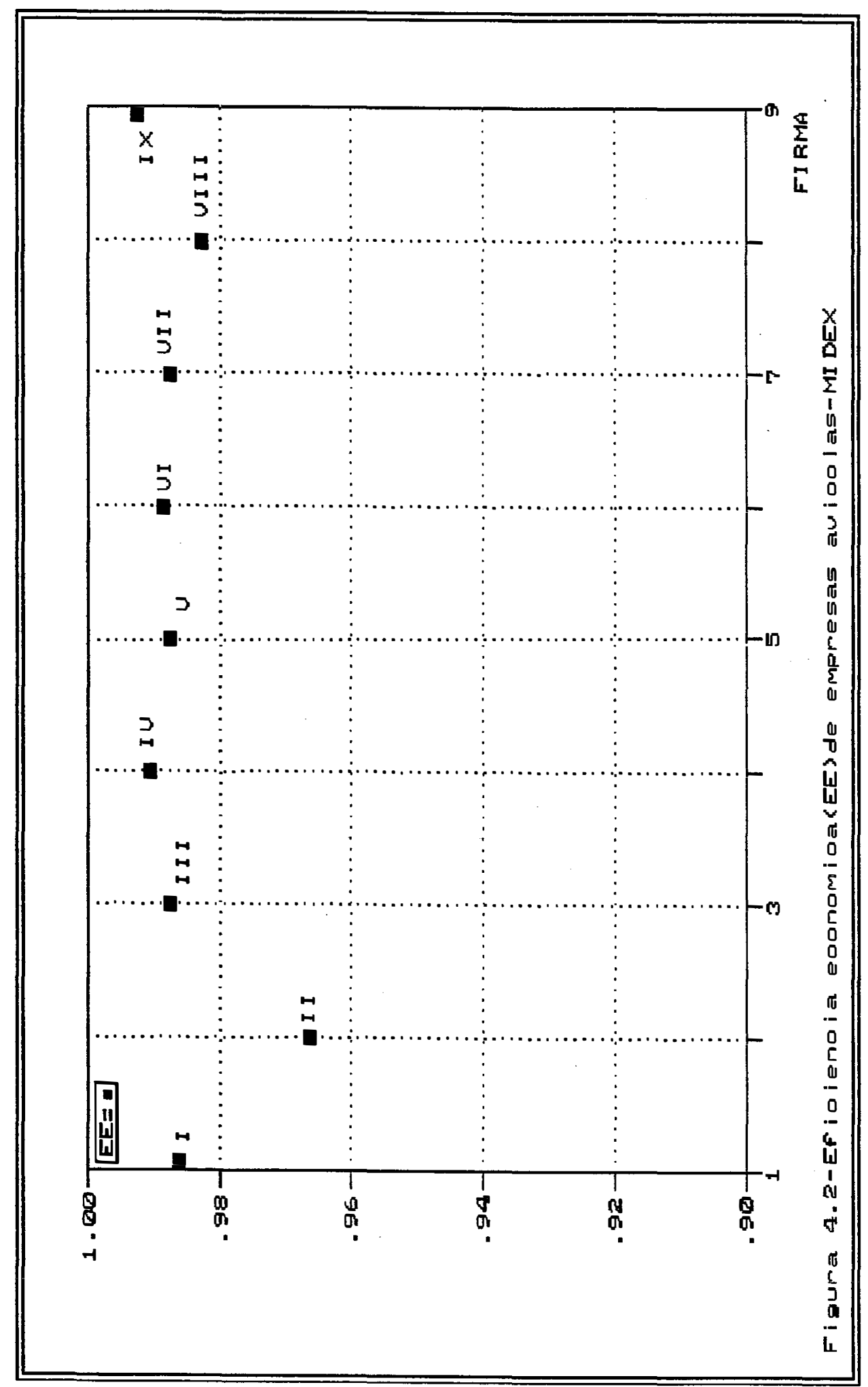




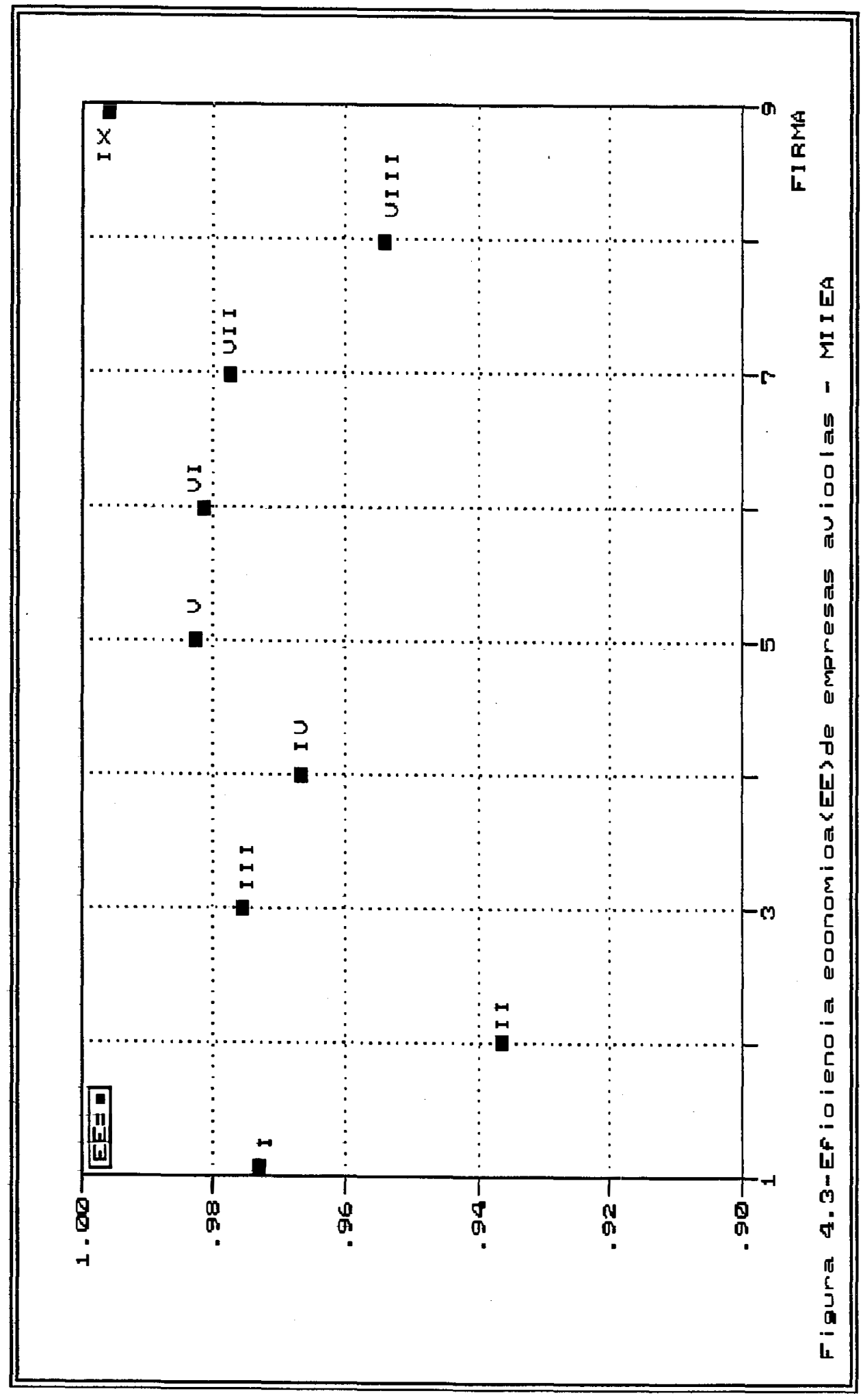


Neste ponto do trabalho torna-se importante tecer algumas considerações no que se refere às estimativas de eficiência econômica obtidas com base nas pressuposições do Modelo I e do Modelo II. A pressuposição de uma eficiência constante para a firma ao longo do tempo é considerada como muito forte, para os autores que trabalharam com dados longitudinais (Pitt \& Lee,1981; Battese e Coelli, 1988; Cornwell et alii, 1990; e Kumbhakar,1990). Segundo Cornwell et alii (1990), as firmas de uma determinada indústria podem responder diferentemente as mudanças no ambiente regulatório, o que implica em níveis variáveis de eficiência ao longo do tempo. De acordo com Lowell (1993), quando a série de tempo é longa ( vários anos), é desejável permitir que a eficiência varie ao longo do tempo e testar a hipótese de eficiência constante.

No presente trabalho, a série de dados é curta e os períodos são compostos por meses (dezesseis meses foram analisados). Neste caso, não é difícil pressupor para a eficiência das empresas avícolas um comportamento constante ao longo do tempo (Modelo II) ou até mesmo independente do tempo (Modelo I). Battese e Coelii (1988) consideraram que a pressuposição de uma eficiência constante para produtores de leite em uma série de três anos era aceitável. Os periodos analisados neste trabalho foram períodos de relativa estabilidade monetária onde provavelmente pouca ou nenhuma mudança ocorreu no ambiente regulatório. Tal fato pode suportar o Modelo II e não causar qualquer impedimento à utilização do Modelo I. As eficiências estimadas por ambos os modelos são altamente correlacionadas, conforme demonstrado na tabela 4.6 e próximas de um. Com relação ao Modelo I, cabe salientar que embora a pressuposição de uma ineficiência independente do tempo permita ignorar a natureza longitudinal dos dados (Pitt \& Lee, 1981 e Greene, 1993) nenhum estudo semelhante foi encontrado na literatura pertinente com dados longitudinais. $\mathrm{Na}$ teoria, a pressuposição de uma eficiência constante para as empresas avícolas conforme considerada no 
Modelo II provavelmente seja a que melhor se ajuste ao tipo de dados utilizados, embora as estimativas tenham sido prejudicadas pelo pequeno número de firmas na amostra. Contudo, tal pressuposição talvez não seja a melhor para uma análise da eficiência econômica de empresas avícolas quando longas séries de tempo forem consideradas e o número de empresas ampliado. O procedimento correto é evidentemente aquele proposto por Lowell (1993), ou seja, permitir que a eficiência varie e testar para ineficiência constante. Infelizmente, os métodos apropriados não estão ainda consolidados (Greene, 1993).

As estimativas de eficiência econômica obtidas com base no Modelo I, figuras A.1 a A.9, no apêndice 1, dão uma idéia do comportamento das empresas no período analisado.

Uma análise das figuras sugere um comportamento variável da eficiência econômica das empresas, mais sugestivo de uma variação ao acaso, sem qualquer tendência no sentido de aumentar ou diminuir ao longo dos dezesseis meses analisados.

Shirota (1995), analisando a eficiência econômica de instituições financeiras no Chile, cobrindo um periodo de aproximadamente oito anos, detectou niveis de eficiência econômica, técnica e alocativa crescentes embora de pequena magnitude. Battese e Coelli (1993) encontraram niveis de eficiência constantes para empresas agrícolas na Índia em determinadas regiōes e em outras níveis crescentes de eficiência em uma série com duração de dez anos. Estes autores concluiram no trabalho acima que para algumas regiões a função de fronteira estimada não era estatísticamente diferente da função média tradicional. 


\section{3 - Análise das relações entre estimativas de eficiência econômica e indicadores zootécnicos de eficiência em uso na produção de frangos de corte.}

O principal indicador zootécnico de eficiência utilizado na produção de frangos de corte é o Índice de Eficiência Produtiva (IEP). No Brasil o IEP é calculado pela seguinte fórmula:

$$
\mathrm{IEP}=\left(\frac{G M D \times V}{C A}\right) \times 100
$$

onde:

GMD é o ganho médio diário do lote de frangos abatido (gramas), calculado como o peso médio do lote dividido pela idade de abate, sendo o peso médio obtido dividindo o peso total do lote de frangos pelo seu número ao abate;

V é a viabilidade (\%), calculada como $100 \%$ menos a porcentagem de aves mortas; e

CA é a conversão alimentar que é calculada como o consumo de ração do lote de frangos, dividido pelo seu peso ao abate.

O IEP tem sido muito utilizado pelas íntegrações avícolas como critério de remuneração dos seus integrados.

Além do IEP e dos seus componentes dados acima, vários outros indicadores zootécnicos de eficiência produtiva tem sido utilizados na avicultura, entre eles, a taxa de mortalidade (MOR), a idade de abate (IDAD), o peso médio (PM), o consumo médio de ração, etc. 
Desse modo, procurou-se, neste estudo, através de uma análise de correlação simples (Tabela 4.10), relacioná-los às estimativas de eficiência econômica.

$\mathrm{Na}$ tabela 4.10 pode-se constatar que o IEP exibiu uma correlação com EE de 0,86 , podendo explicar cerca de $75 \%$ da variação de $E E$. Os demais indicadores zootécnicos de eficiência também são correlacionados em algum grau a $E E$ e podem explicar menos do que $50 \%$ da variação de $E E$, conforme consta da tabela 4.10 .

Tabela 4.10- Análise de correlação entre estimativas de eficiência econômica ${ }^{a}$ (EE) e indicadores zootécnicos de eficiência.

\begin{tabular}{|c|c|c|c|c|c|c|c|}
\hline & $\overline{\overline{E E}}$ & CA & IDAD & PM & MOR & GMD & IEP \\
\hline$\overline{\overline{E E}}$ & 1,00 & & & & & & \\
\hline CA & $-0,74$ & 1,00 & & & & & \\
\hline IDAD & $-0,40$ & 0,85 & 1,00 & & & & \\
\hline PM & $-0,04$ & 0,63 & 0,88 & 1,00 & & & \\
\hline MOR & $-0,14$ & 0,26 & 0,26 & 0,36 & 1,00 & & \\
\hline GMD & 0,36 & 0,15 & 0,43 & 0,81 & 0,37 & 1,000 & \\
\hline IEP & 0,86 & $-0,61$ & $-0,28$ & 0,17 & $-0,10$ & 0,65 & 1,00 \\
\hline \multicolumn{8}{|c|}{$\begin{array}{l}\text { As estimativas de eficiência econômica consideradas na análise de correlação foram apenas } \\
\text { aquelas estimadas com base no MIDMN. }\end{array}$} \\
\hline $\begin{array}{l}\text { descrit } \\
\text { MIDEX } \\
\text { nara a }\end{array}$ & $\begin{array}{l}\text { apên } \\
\text { s das } \\
\text { MIIEA }\end{array}$ & $\begin{array}{l}2 d \\
\text { hativas } \\
\text { os ind }\end{array}$ & $\begin{array}{l}\text { trabs } \\
\text { eficié } \\
\text { ores }\end{array}$ & $\begin{array}{l}\text { estão } \\
\text { econ } \\
\text { cnicos }\end{array}$ & isponiv & $\begin{array}{l}\text { as } \mathrm{e} \\
\text { ase nc } \\
\text { por er }\end{array}$ & $\begin{array}{l}\text { tísticas } \\
\text { MIDMN, } \\
\text { esas e }\end{array}$ \\
\hline
\end{tabular}




\section{CONCLUSÕES}

O segmento de produção de frangos de corte é um segmento básico da Indústria avícola. Esta, insere-se em um mercado competitivo, onde operar com eficiência econômica é fundamental para a sobrevivência da firma. Em mercados competitivos, torna-se extremamente importante monitorar a eficiência econômica das empresas, uma vez que, as pouco eficientes serão certamente afastadas do mercado. Nesta perspectiva, 0 presente trabalho estimou a eficiência econômica do segmento de produção de frangos de corte de algumas empresas avícolas no Brasil. Os resultados do trabalho permitiram concluir que:

i) A expectativa sobre a utilização de formas flexíveis para a função de custo ( translog) e para a função de densidade de probabilidade da variável aleatória que capta a ineficiência da firma (distribuição normaltruncada com moda diferente de zero) não foi satisfeita. As análises apontaram formas funcionais mais simples tanto para a função de custo, como para a função de densidade da variável aleatória que capta a ineficiência, respectivamente uma função log-linear do tipo Cobb-Douglas e uma função de distribuição meio-normal;

ii) No modelo mais coerente com a teoria de funções fronteira ( Modelo II ) para dados longitudinais compostos de séries de curta duração, a hipótese de uma ineficiência custo igual a zero com base no parâmetro $\lambda$, que incorpora a ineficiência da firma, não foi rejeitada para as empresas analisadas, quando o teste considerado foi o teste de $t$. Tal fato talvez possa ser atribuido ao pequeno número de empresas amostradas, o que provavelmente superestimou os erros-padrão das estimativas dos parâmetros. Tal conclusão talvez possa ser suportada pelo fato da variância da variável aleatória, que capta a ineficiência da firma, predominar sobre a variável 
aleatória que capta ruidos estatísticos, erros de medição e outros fatores fora do controle da firma. O emprego do Modelo I para a amostra utilizada (série de tempo de curta duração), embora não considerado na literatura consultada, é válido mediante a pressuposição de ineficiência da firma independente do tempo. Neste modelo a hipótese de ineficiência custo igual a zero com base no parâmetro $\lambda$ foi rejeitada quando $o$ teste utilizado foi $o$ teste t. Para estudos com séries de tempo longas, recomenda-se a utilização de modelos apoiados na pressuposição de um comportamento variável para a eficiência da firma, testanto-se complementarmente para níveis de eficiência constantes;

iii ) O segmento de produção de frangos de corte no período entre janeiro de 1995 e abril de 1996 operou com alta eficiência econômica. Isto equivale dizer que o segmento operou muito próximo e até mesmo nas fronteiras de custo e de produção, dada a tecnologia (Modelos I e II). De acordo com a teoria econômica, tal resultado caracteriza o segmento como realmente competitivo. O domínio sobre a tecnologia é grande na produção de frango de corte, além disso as empresas analisadas estão entre as vinte maiores em produção do pais, acumulando grande experiência. Os fatores de produção, pintos de um dia e ração estão sob estrito controle das empresas. Material genético de alta qualidade, rações bem elaboradas e de custo mínimo, rígido programa sanitário e de manejo são características do segmento de produção de frango de corte. Operar próximo à fronteira de custo além de caracterizar o segmento como competitivo, traz por outro lado como implicação, o fato de que ganhos em produtividade só ocorrerão mediante a introdução de novas tecnologias. Existe a opinião de que os maiores avanços ocorrerão na esfera do manejo. Contudo existem sinais evidentes de que avanços também ocorrerão na esfera da nutrição; e

iv) $O$ indice de eficiência produtiva (IEP), muito utilizado como indicador de eficiência zootécnica na produção de frangos de corte e como critério para remuneração de integrados, poderá ser utilizado, dada a 
correlação obtida com a estimativa de eficiência econômica, como um indicador complementar de eficiência econômica. Os outros indicadores de eficiência zootécnica como por exemplo, o ganho de peso, a conversão alimentar, o peso médio, a mortalidade, etc, exibem correlações de média a baixa com as estimativas de eficiência econômica obtidas neste trabalho. Não devem portanto, serem utilizados como indicadores complementares de eficiência econômica.

Este trabalho traz consigo algumas limitações. A primeira está relacionada ao modelo utilizado, ou seja, um modelo com um produto e dois fatores de produção (pintos de um dia e ração). Este é um modelo simples, embora pintos de um dia e ração representem aproximadamente $86 \%$ dos custos de produção de frangos. O modelo adequado deve computar todos os custos do segmento analisado. Uma segunda limitação do trabalho é a análise de apenas um segmento do setor. O segmento de produção de frangos de corte representa apenas parte da indústria do frango. 0 modelo adequado deve estimar a eficiência econômica das empresas com relação ao produto processado ou ao mix de produtos. Isto permite captar no modelo todos os custos relativos à atividade das empresas. Contudo as dificuldades neste sentido são grandes. A obtenção dos dados de custos das empresas é um processo complexo, que não ocorrerá sem que alguns acordos institucionais sejam estabelecidos. Uma terceira limitação do trabalho foi o pequeno número de empresas analisadas, embora estas representem aproximadamente $20 \%$ da produção de frangos de corte do Brasil. Este número poderia ser bem maior caso as empresas não relutassem em ceder os dados. Uma quarta limitação do trabalho foi o curto periodo analisado, decorrente da dificuldade das empresas em tornar disponiveis no curto prazo dados com um horizonte temporal mais amplo.

Como contribuição científica, cabe salientar, que este trabalho é pioneiro em análise de eficiência econômica de empresas avícolas, utilizando o 
método de fronteiras estocásticas. Contribuiu também no sentido de tornar disponível ao setor agrícola brasileiro um instrumental analítico da eficiência econômica que poderá ser utilizado por grupos de empresas privadas, cooperativas, associações de produtores e sistemas de produção individuais a qualquer momento.

Como sugestão à pesquisa acredita-se que a análise de toda a cadeia produtiva de frangos de corte e de muitas outras cadeias produtivas da agricultura brasileira se constitua numa linha de estudos importante. Além disso, outros instrumentais de estimação de fronteiras de custo, lucro e produção, como por exemplo o método da programação pura, deverão ser testados e utilizados na medição da eficiência econômica de empresas agrícolas no Brasil, comparativamente ao método econométrico. 


\section{REFERÊNCIAS BIBLIOGRÁFICAS}

AFRIAT, S. N. Efficiency estimation of production functions. International Economic Review 13(3): 568 - 598, 1972.

AIGNER, D. J. ; LOVELL, C. A. K. and SCHMIDT, P.J. Formulation and estimation of stochastic frontier production function models. Journal of Econometrics 6: 21 - 37, 1977.

AIGNER, D. J. \& CHU, S. F. On estimation the industry production function. American Economic Review 58(4): 826 - 839, 1968.

ALI, M. \& CHAUDHRY, M. A. Inter - regional Farm Efficiency in Pakistan's Punjab: A Frontier production Function Study. Journal of Agricultural Economics 41(1): 62 - 74, 1990.

ALI, M. \& FLINN, J.C. Profit efficiency among Basmati rice producers in Pakistan Punjab. American Journal of Agricultural Economics, 71(2):303-310,1989.

ASSOCIAÇÃO PAULISTA DE AVICULTURA. Tendências mundiais na produção, comércio e consumo de carne de frangos. Aves e Ovos, 4: 8 48, 1995.

ATKINSON, S.E \& CORNWELL, C. Parametric estimation of technical and allocative ineficiency with panel data. International Economic Review, 35(1): 231-243, 1994.

BATTESE, G. E. \& COELLI, T.J. Prediction of firm-level technical efficiencies with a generalized frontier production function and panel data. Journal of Econometrics 38, 387-399, 1988.

BATTESE, G. E. Frontier production functions and technical efficiency: A Survey of empirical applications in agricultural economics. Agricultural Economics 7(3/4): 185 - 208, 1992. 
BATTESE, G. E. \& COELLI, T. J. Frontier production functions, technical efficiency and panel data: with application to paddy farmers in India. The Journal of Productivity Analysis 5, 155-169, 1992.

BATTESE, G. E. \& TESSEMA, G. A. Estimation of stochastic frontier production functions with time-varying parameters and technical efficiencies using panel data from Indian villages. Agricultural Economics 9, 313$333,1993$.

BAUER, P. W. Recent development in the econometric estimation of frontiers. Journal of Econometrics 46(1/2): 39 - 56, 1990.

BAUMOL,W.J.; PANZAR, J.C. \& WILLIQ,R.D. Contestable markets and the theory of industry structure. Harcourt Brace Jovanovich Publishers, 1988 p.151-168.

BERNDT, E. R. The Pratice of Econometrics: Classic and Contemporary, Addison-Wesley, 1991. 702p.

BRAVO-URETA, B. E. \& RIEGER, L. Alternative production frontier methodologies and dairy farm efficiency. Journal of Agricultural Economics, $41(2): 215-226,1990$.

BRAVO-URETA, B. E. \& EVESON, R, E. Efficiency in agricultural production:

The case of peasant farmers in eastern Paraguay. Agricultural economics, 10(1): 27 - 37, 1994.

BRAVO-URETA, B. E. \& RIEGER, L. Dairy farm efficiency measurement using stochastic frontiers and neoclassical duality. American Journal of Agricultural Economics 73(2): 421 - 426.1991.

CHAMBERS, R. G. Applied Production Analysis. New York: Cambridge University Press, New York, 1988,331p.

CHIANG, A. C. Fundamental Methods of Mathematical Economics. Third Edition. New York; McGrawn Hill Book, 1984. 788 p. 
CHRISTENSEN,L.R. \& GREENE,W.H. Economics of scale in U.S. electric power generation. Journal of Political Economy 84(4):655-666,1976.

CORNWELL, C. ; SCHMIDT, P. \& SICKLES, R.C. Production frontiers with cross-sectional and time-series variation in efficiency levels. Journal of Econometrics 46, 185-200,1990.

FAO. SITUATION Y PERSPECTIVAS DE LOS PRODUCTOS BASICOS - 1995. Roma.

FARREL, M., J. A measurement of productive efficiency. Journal of The Royal Statistical Society. Série A. 120: 254 - 290,1957.

FORSUND, F. R. \& JANSEN, E. S. On estimating average and best pratice homothetic production functions via cost functions. International Economic Review 18(2): 463 - 476, 1977.

FORSUND, F. R. \& HJALMARSSON, L. Generalized Farrel measures of efficiency: An application to milk processing in swedish dairy plants. Economic Journal 89: 274 - 315, 1979.

FORSUND, F. R.; LOVELL, K. C. A \& SCHMIDT, P. A survey of frontier production functions and of their relationship to efficiency measurement. Journal of Econometrics 13: 5-25, 1980.

FRIED, H.; LOVELL, K. C. A. \& SCHMIDT, S. Measurement of productive efficiency: Techniques and Applications. New York: Oxford University Press. 1993. 426p.

GREENE, W. H. Maximun likelihood estimation of econometric frontier functions. Journal of Econometrics. 13:27 - 56, 1980.

GREENE, W. H. The econometric approach to efficiency analysis. In: The Measurement of Productive Efficiency. New York: Oxford University Press, 1993, p. 68-119.

GREENE, W. H." LIMDEP Computer program: Version 6.0" Econometric software, Belport, N.Y. 1992. 
HEATHFIELD, D.F. \& WIBE, S. An Introduction to Cost and Production Functions. Atlantic Highlands, NJ, Humanities Press International, 1987, $193 p$.

KALIRAJAN, K.P. On measuring economic efficiency. Journal of Applied Econometrics, 5, 75 - 85, 1990.

KOPP, L. \& DIEWERT,E. The decomposition of frontier cost function deviations into measures of technical and allocative efficiency. Journal of Econometrics , 19 (2/3):319-332,1982.

KUMBHAKAR, S. C.; BISWAS, B. \& BAILEY, D.V. A study of economic efficiency of Utah dairy farmers: A system approach. The Review of Economics and Statistics 71(4): 595 - 604, 1989.

KUMBHAKAR, S. C. \& HJALMARSSON, L. Technical efficiency and technical progress in Swedish dairy farms. In: The measurement of productive efficiency. Techniques and Applications. New York: Oxford University Press.1993 p.256 -270.

KUMBHAKAR, S. C. Efficiency estimation in a profit maximising model using flexible production function. Agricultural Economics, 10 ( 2 ):143-152,1994

LOVELL, K. C. A. \& SCHMIDT, P. A comparison of alternative approaches to the measurement of productive efficiency. In: Applications of modern production theory. Boston, Kluwer Academic Publishers, 1988, p. 3 - 32.

LOVELL, K.C.A. Production frontiers and productive efficiency. In: The measurement of productive efficiency. Techniques and Applications. New York. Oxford University Press.1993 p.3 -

MARQUES, P. V. Economia da integração vertical na avicultura de corte do estado de São Paulo. Piracicaba, ESALQ/USP,1991. Tese de Livre Docência. 133p. 
MEEUSEN, W. \& BROECK, J. Van Den. Efficiency estimation from CobbDouglas production functions with composed error. International Economic Review 18(2): 435 - 444, 1977.

PARIKH, A. \& SHAH, M.K. Measurement of cost inefficiency with safety first measure of risk. Agricultural Economics, 11(2/3):197-206,1994.

PITT ,M.M. \& LEE, L.F. The measurement and sources of technical inefficiency in the indonesian weaving industry. The Journal of Development Economics 9, 43-64, 1981.

PRIOR, J. Estrutura da moderna empresa avícola. In: Manejo de frangos. Campinas, APINCO, 1994, p. 11 - 14.

RICHMOND, J. Estimating the efficiency of production. International Economic Review. 15(2): 515 - 521, 1974.

RIZZI, A.T. Mudanças tecnológicas e reestruturação da indústria agroalimentar:

O caso da indústria de frangos no Brasil. Tese de Doutorado. UNICAMP,1993. 194p.

SCHMIDT, P. \& LOVELL, K. C. A. Estimating technical and allocative inefficiency relative to stochastic production and cost frontiers. Journal of Econometrics, 9;343-366,1979.

SHIROTA, R. Efficiency in financial intermediation: A study of the chilean banking industry. Tese de PhD, The Ohio State University, 1995.

STEVENSON, R.E. Likelihood functions for generalized stochastic frontier estimation. Journal Of Econometrics, 13:57-66,1980.

TAYLOR, T. G.; .DRUMMOND, H.E. \& GOMES, A.T. Agricultural credit programs and production efficiency: An analysis of traditional farming in southeastern Minas Gerais, Brazil. American Journal Agricultural Economics 66(1): 110 - 119, 1986.

VARIAN, H. R. Microeconomic analysis. New York: W.W.Norton \& Company, $1992.548 p$. 
WRIGHT, C. Empresas lideres 1995. Industria Avicola, 42(1): 8 - 30, 1995. 
APÊNDICE 1 


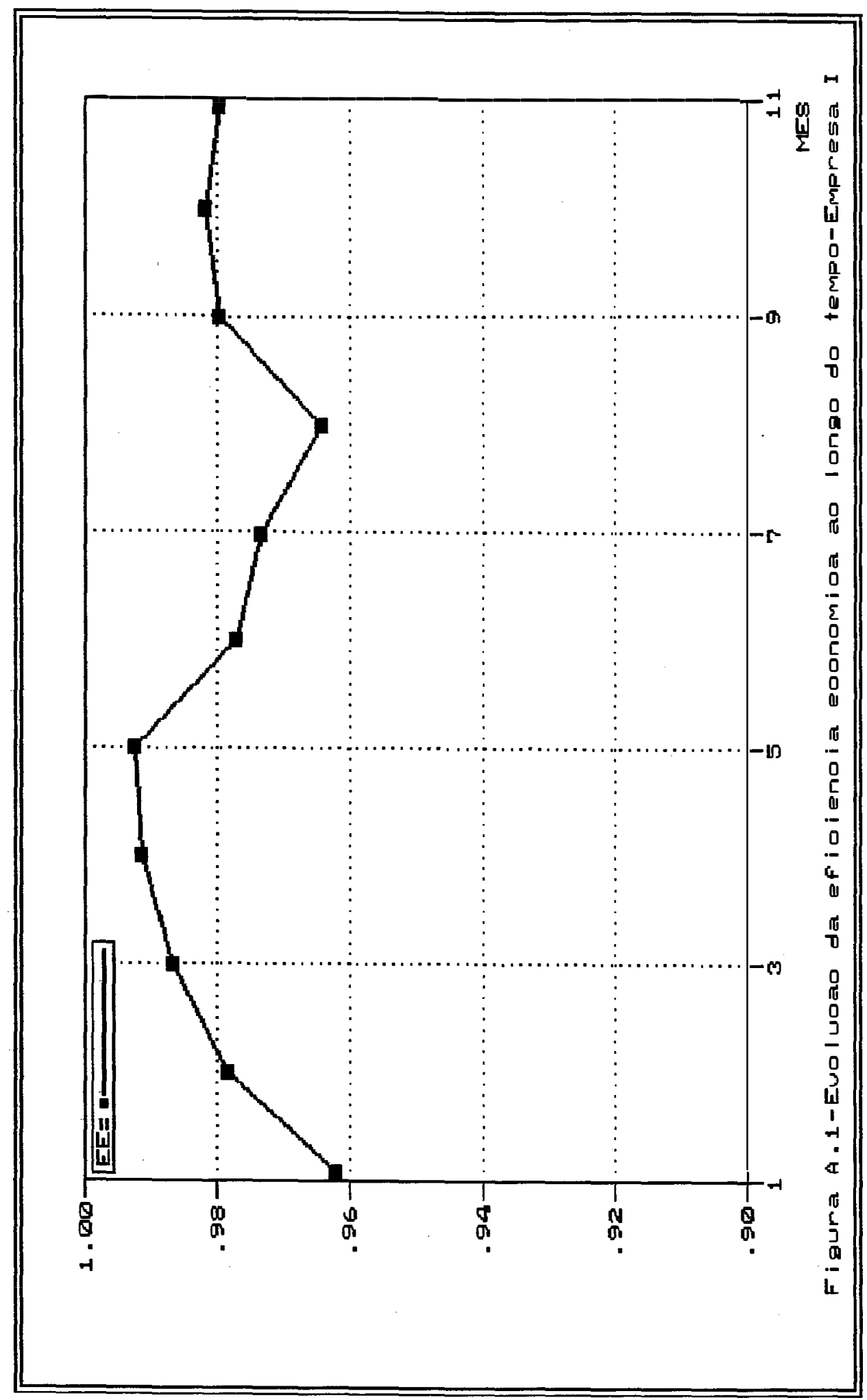




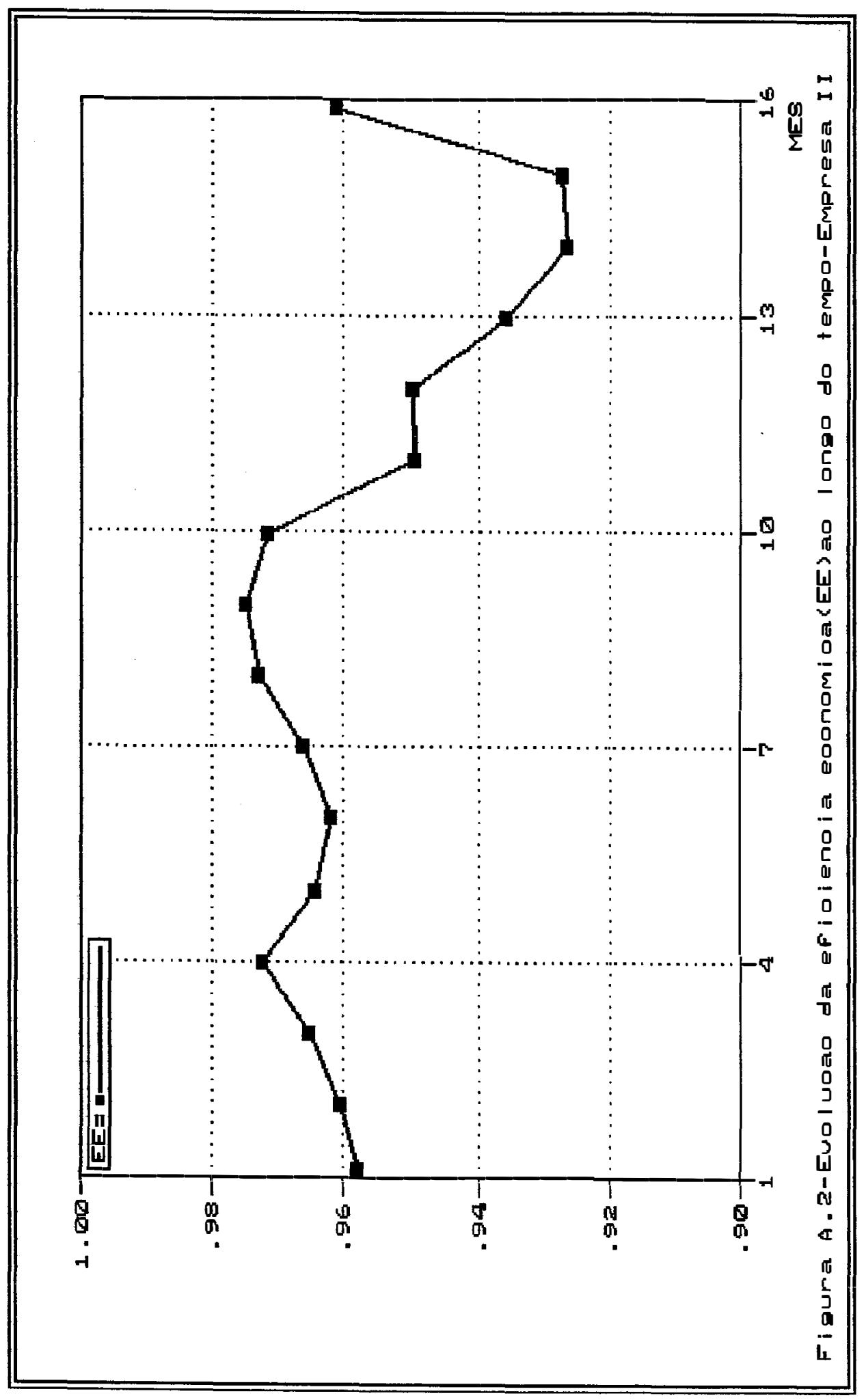




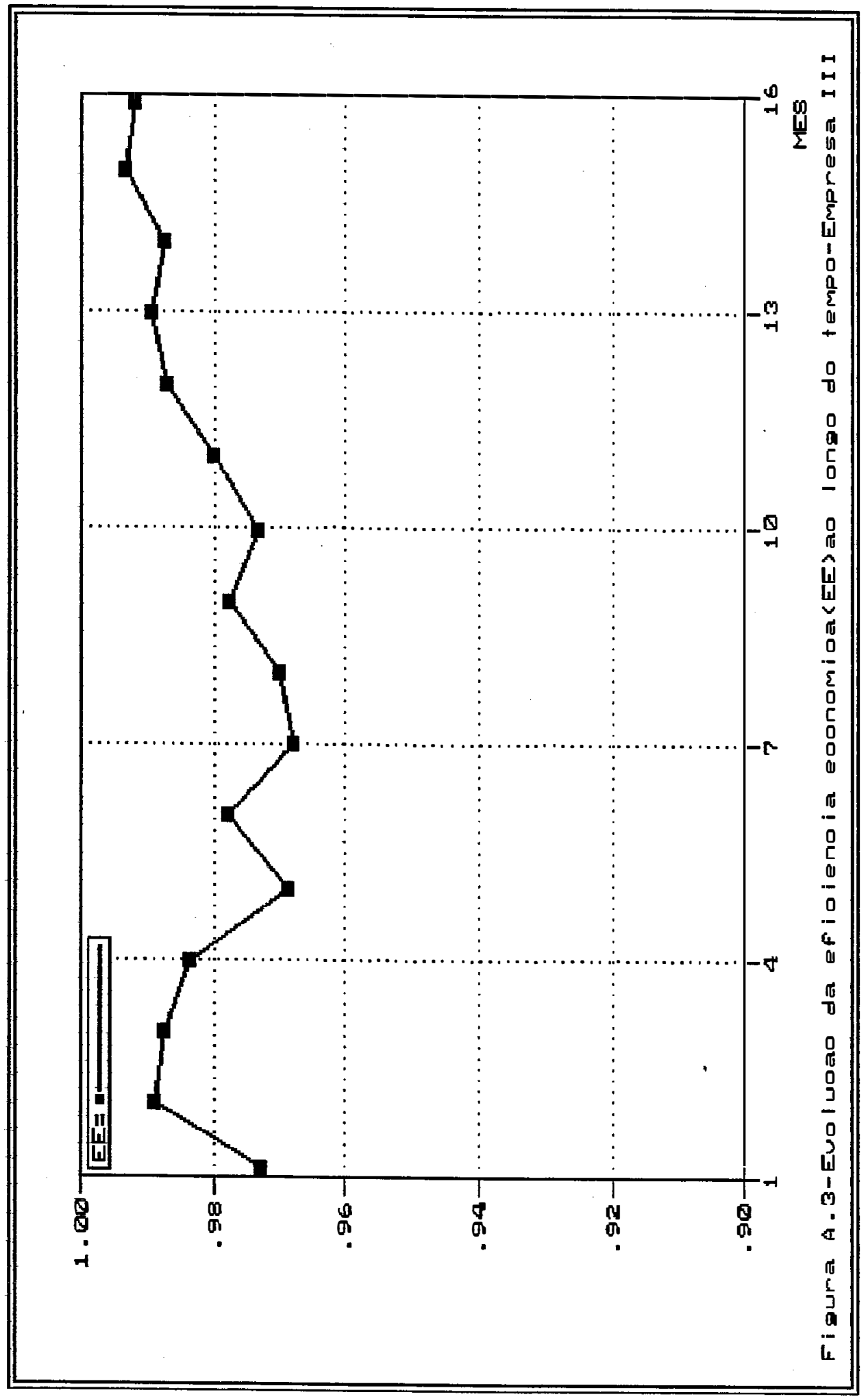




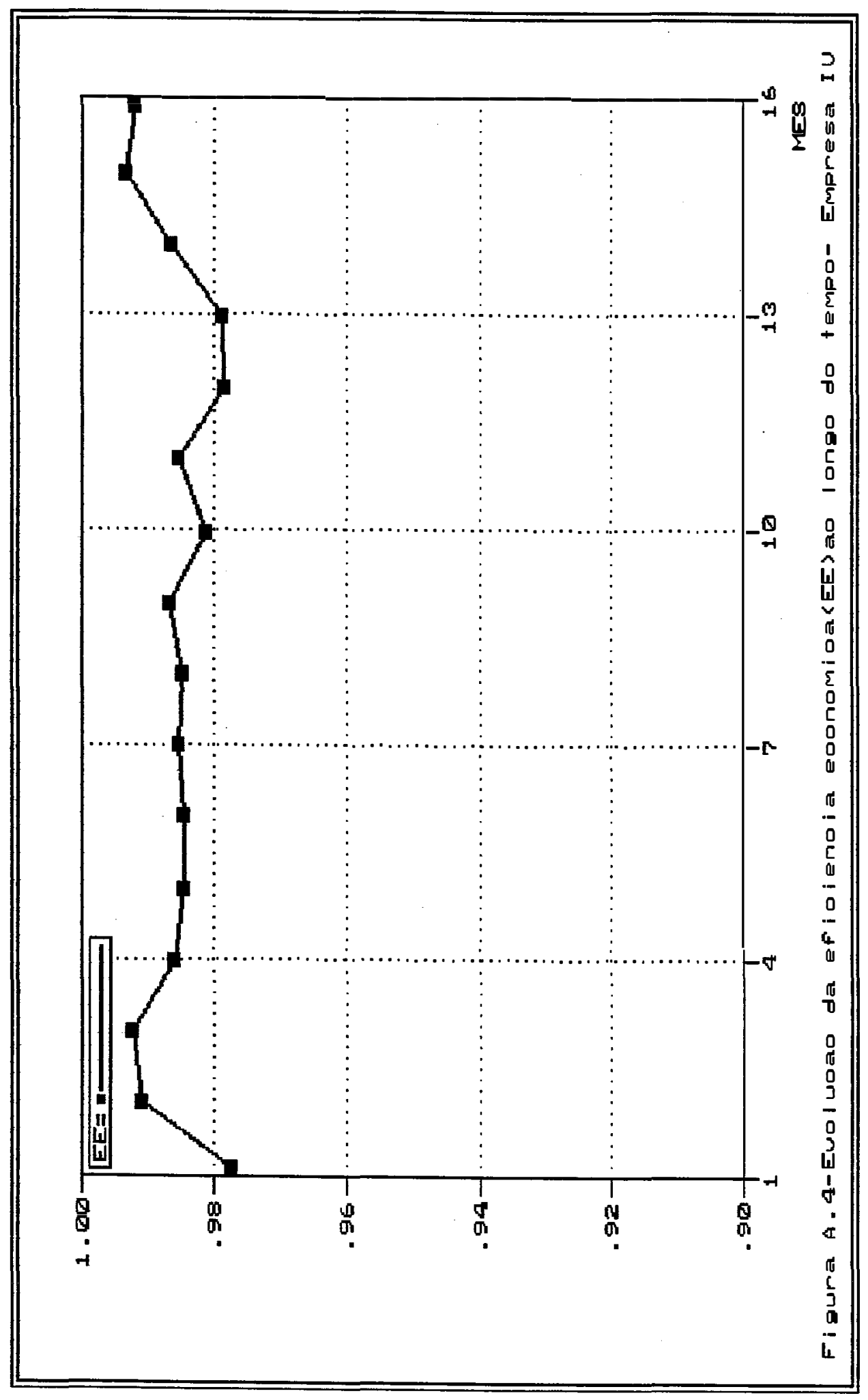




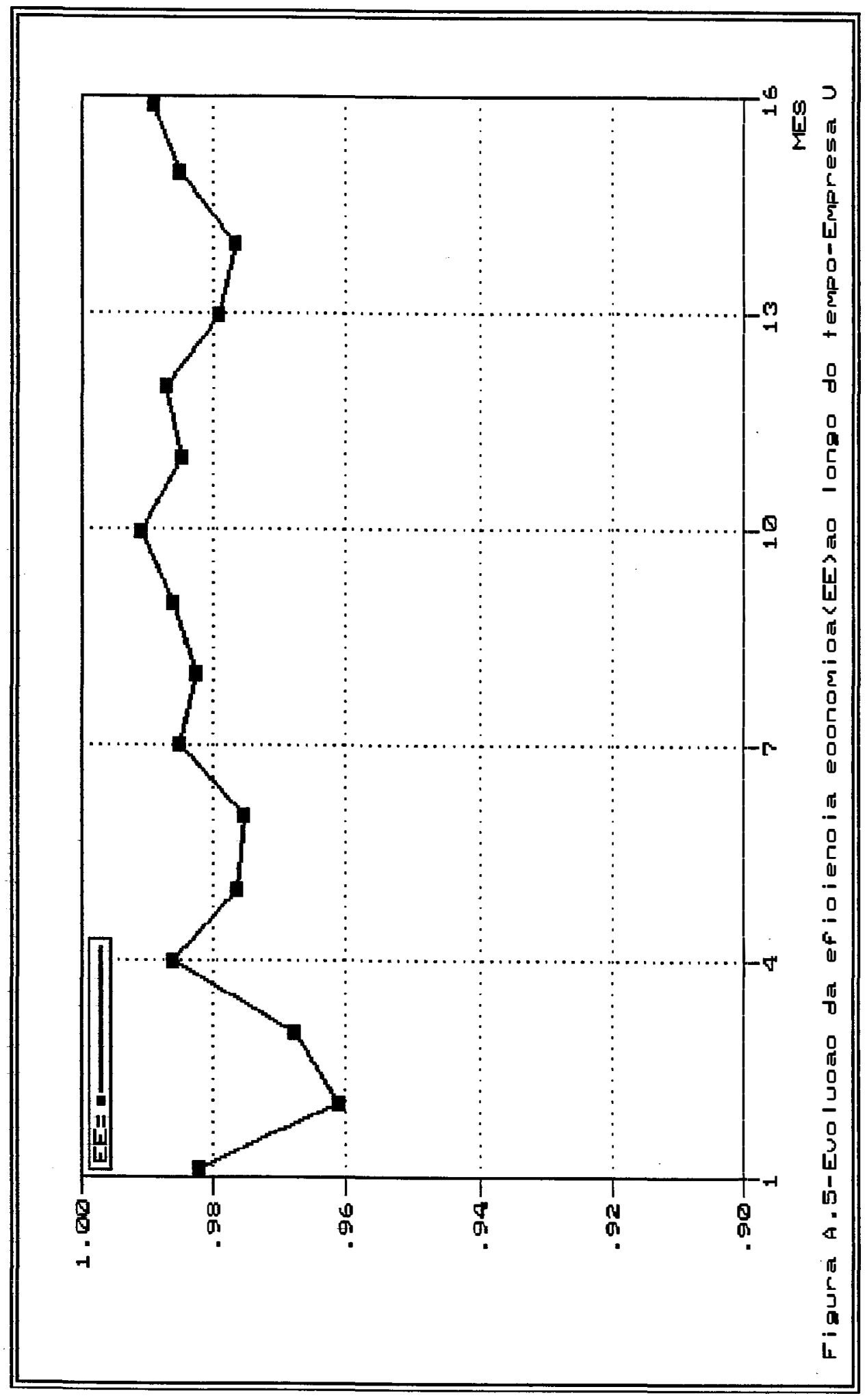




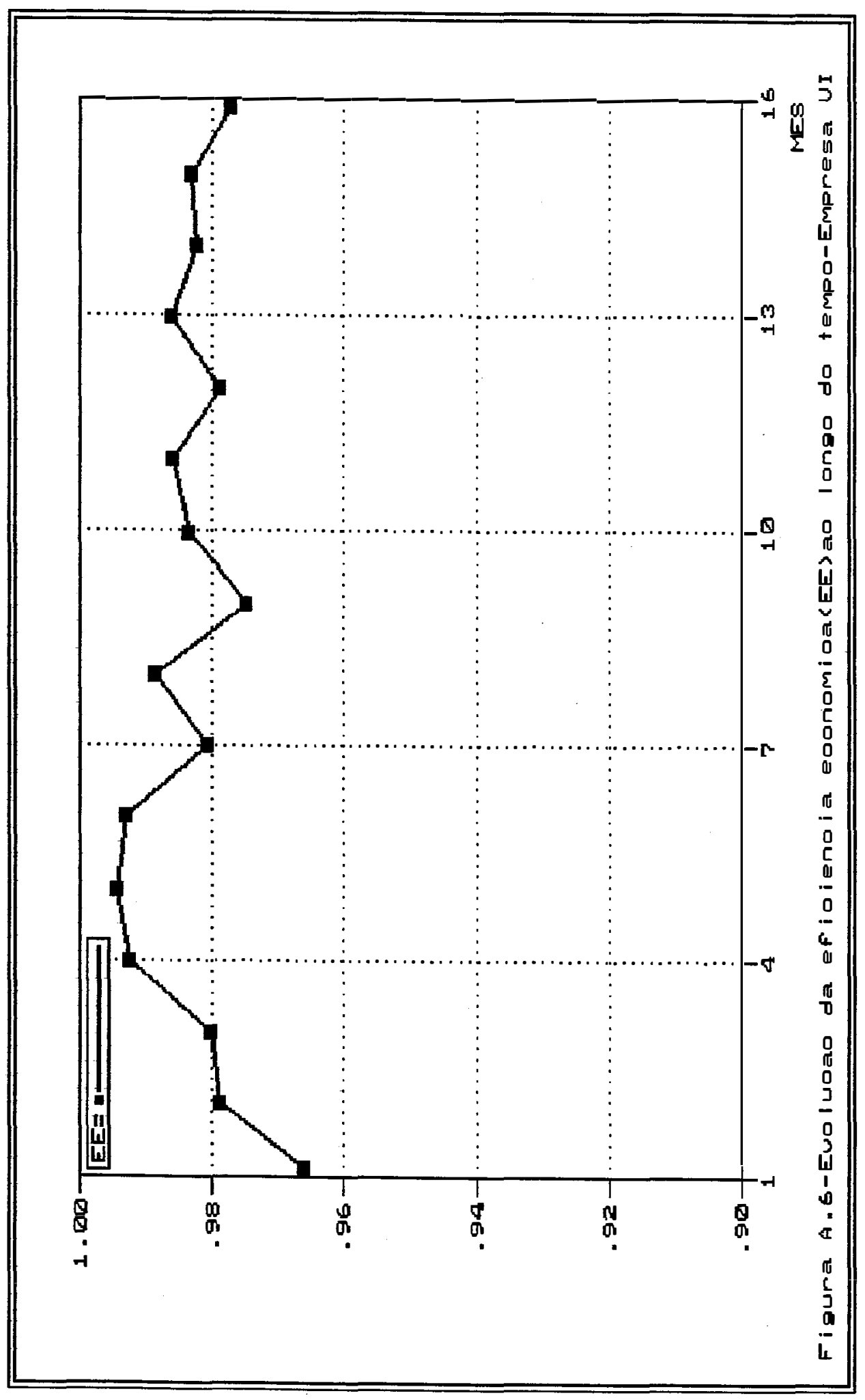




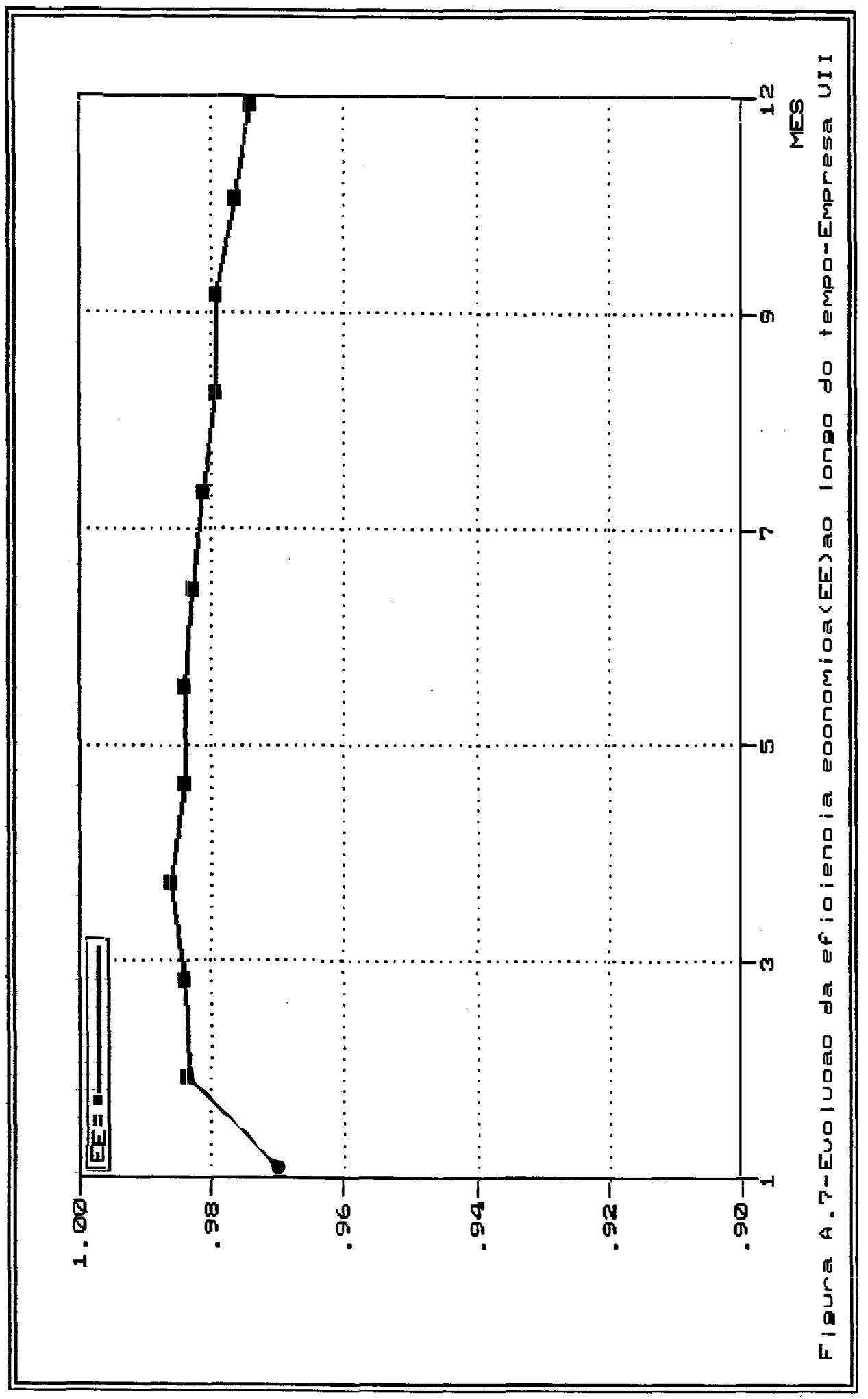




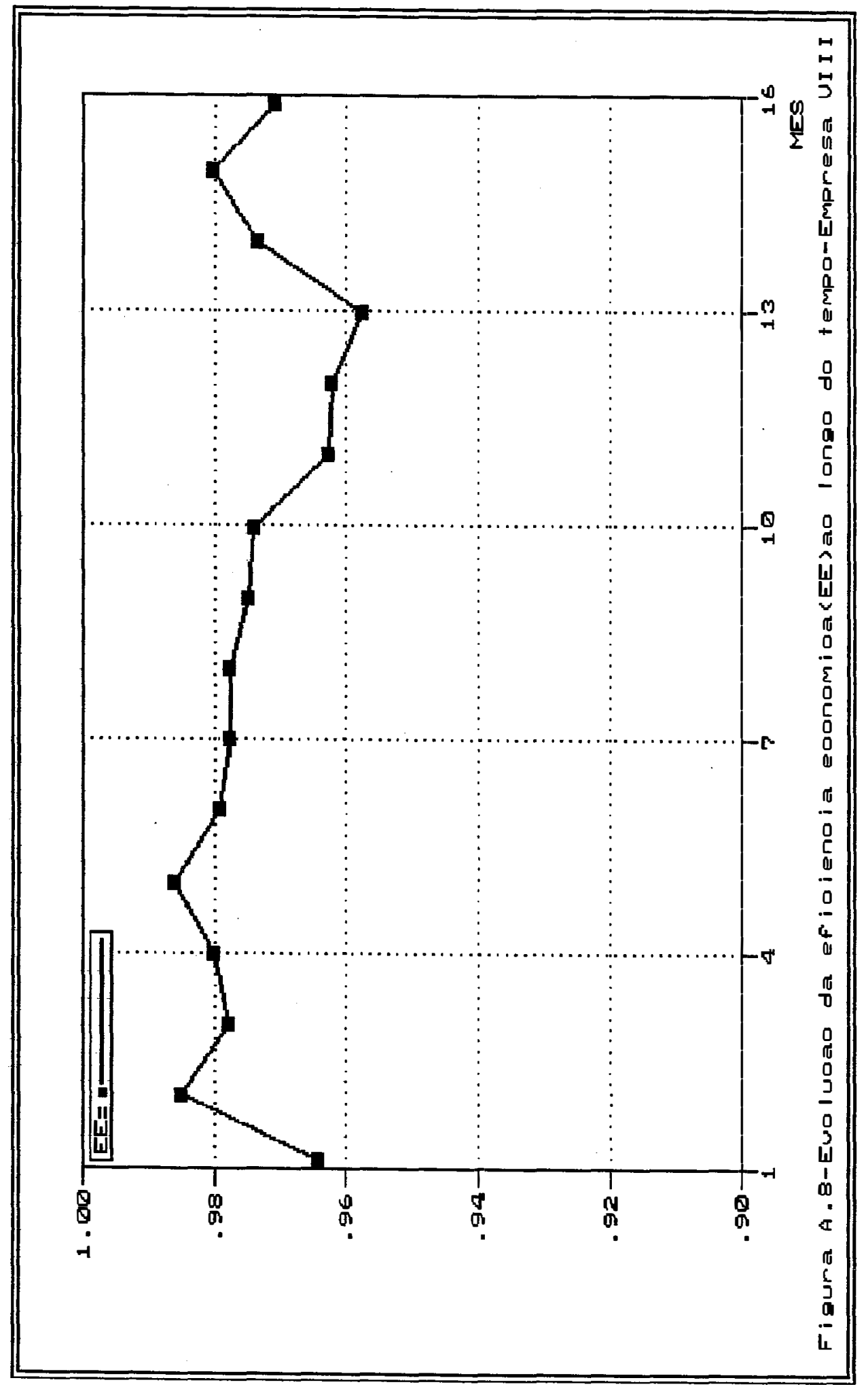




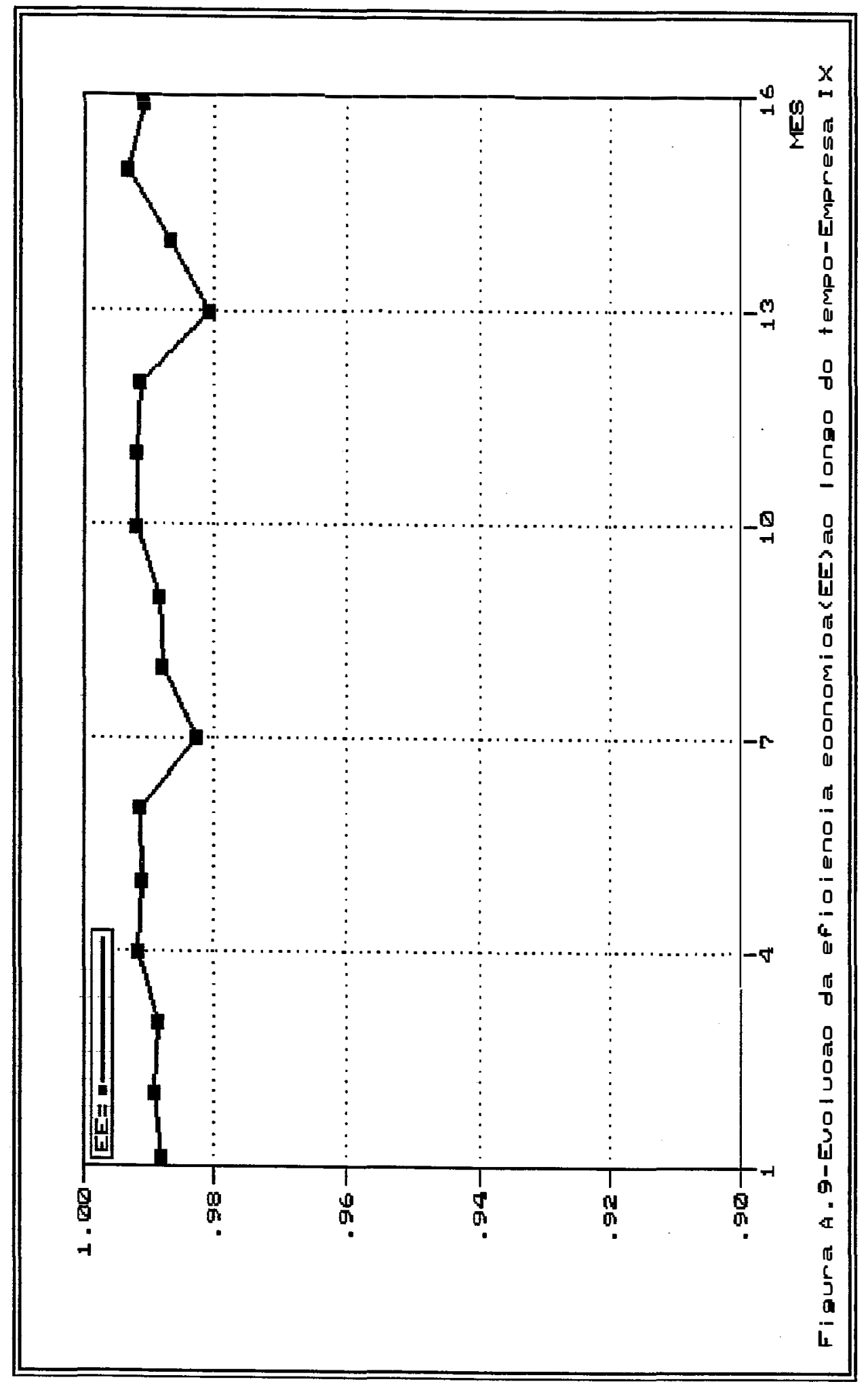


APÊNDICE 2 
Tabela B.1- Estatística descritiva das estimativas de eficiência econômica (EE) e dos indicadores zootécnicos de eficiência da empresa I.

\begin{tabular}{lccccc}
\hline \hline Variável & Número & Mínimo & Máximo & Média & D.Padrão \\
\hline \hline EE(MIDMN) & 11 & 0,9621 & 0,9927 & 0,9790 & 0,0097 \\
EE(MIDEX) & 11 & 0,9734 & 0,9946 & 0,9865 & 0,0066 \\
EE(MIIDEA) & 11 & 0,9487 & 1,0000 & 0,9730 & 0,0181 \\
CA & 11 & 1,9600 & 2,0700 & 2,0155 & 0,0375 \\
IDAD & 11 & 42,880 & 46,670 & 45,316 & 1,0720 \\
MOR & 11 & 4,7300 & 7,0900 & 5,5555 & 0,7048 \\
IEP & 11 & 204,94 & 241,07 & 221,26 & 9,6562 \\
PM & 11 & 1,9900 & 2,2500 & 2,1382 & 0,0804 \\
GMD & 11 & 0,0447 & 0,0496 & 0,0472 & 0,0015 \\
\hline \hline
\end{tabular}

Fonte: Dados da pesquisa.

Tabela B.2- Estatística descritiva das estimativas de eficiência econômica (EE) e dos indicadores zootécnicos de eficiência da empresa II.

\begin{tabular}{lccccc}
\hline \hline Variável & Número & Mínimo & Máximo & Média & D.Padrão \\
\hline \hline EE(MIDMN) & 16 & 0,9266 & 0,9748 & 0,9574 & 0,0156 \\
EE(MIDEX) & 16 & 0,9285 & 0,9842 & 0,9663 & 0,0184 \\
EE(MIIDEA) & 16 & 0,9049 & 0,9548 & 0,9364 & 0,0160 \\
CA & 16 & 2,1100 & 2,2200 & 2,1412 & 0,0381 \\
ID & 16 & 46,300 & 48,500 & 47,2625 & 0,6530 \\
MOR & 16 & 3,0000 & 6,0000 & 4,6812 & 0,8841 \\
IEP & 16 & 186,57 & 215,66 & 202,92 & 8,7248 \\
PM & 16 & 2,0400 & 2,2500 & 2,1525 & 0,0670 \\
GMD & 16 & 0,0427 & 0,0479 & 0,0455 & 0,0014 \\
\hline \hline
\end{tabular}

Fonte: Dados da pesquisa . 
Tabela B.3- Estatística descritiva das estimativas de eficiência econômica (EE) e dos indicadores zootécnicos de eficiência da empresa III.

\begin{tabular}{lccccc}
\hline \multicolumn{1}{c}{ Variável } & Número & Mínimo & Máximo & Média & D.Padrão \\
\hline \hline EE(MIDMN) & 16 & 0,9679 & 0,9936 & 0,9813 & 0,00288 \\
EE(MIDEX) & 16 & 0,9786 & 0,9950 & 0,9878 & 0,0052 \\
EE(MIIDEA) & 16 & 0,9512 & 1,0000 & 0,9754 & 0,0160 \\
CA & 16 & 2,0100 & 2,1600 & 2,0837 & 0,0396 \\
IDAD & 16 & 46,800 & 48,750 & 47,900 & 0,5518 \\
MOR & 16 & 3,0000 & 8,2300 & 5,7050 & 1,6343 \\
IEP & 16 & 220,76 & 249,20 & 230,97 & 9,2735 \\
PM & 16 & 2,3800 & 2,5500 & 2,4437 & 0,0447 \\
GMD & 16 & 0,0494 & 0,0524 & 0,0510 & 0,0006 \\
\hline \hline
\end{tabular}

Fonte: Dados da pesquisa.

Tabela B.4- Estatística descritiva das estimativas de eficiência econômica (EE) e dos indicadores zootécnicos de eficiência da empresa IV.

\begin{tabular}{cccccc}
\hline \hline Variável & Número & Mínimo & Máximo & Média & D.Padrão \\
\hline \hline EE(MIDMN) & 16 & 0,9777 & 0,9935 & 0,9857 & 0,0049 \\
EE(MIDEX) & 16 & 0,9861 & 0,9950 & 0,9908 & 0,0027 \\
EE(MIIDEA) & 16 & 0,9528 & 0,9923 & 0,9666 & 0,0113 \\
CA & 16 & 1,9200 & 2,0200 & 1,9756 & 0,0273 \\
IDAD & 16 & 41,100 & 43,680 & 42,481 & 0,7957 \\
MOR & 16 & 5,1800 & 6,1300 & 5,6143 & 0,2846 \\
IEP & 16 & 208,79 & 231,41 & 220,31 & 6,5845 \\
PM & 16 & 1,8800 & 2,0800 & 1,9556 & 0,0508 \\
GMD & 16 & 0,0444 & 0,0476 & 0,0460 & 0,0008 \\
\hline \hline
\end{tabular}

Fonte: Dados da pesquisa. 
Tabela B.5- Estatística descritiva das estimativas de eficiência econômica (EE) e dos indicadores zootécnicos de eficiência da empresa V.

\begin{tabular}{cccccc}
\hline \hline Variável & Número & Mínimo & Máximo & Média & D.Padrão \\
\hline \hline EE(MIDMN) & 16 & 0,9612 & 0,9912 & 0,9812 & 0,0081 \\
EE(MIDEX) & 16 & 0,9714 & 0,9937 & 0,9877 & 0,0058 \\
EE(MIIDEA) & 16 & 0,9618 & 1,0000 & 0,9828 & 0,0193 \\
CA & 16 & 1,9500 & 2,0900 & 2,0087 & 0,0320 \\
IDAD & 16 & 43,710 & 46,380 & 45,077 & 0,6736 \\
MOR & 16 & 3,9600 & 8,3200 & 6,2962 & 1,0844 \\
IEP & 16 & 212,59 & 233,18 & 221,69 & 5,9870 \\
PM & 16 & 2,0600 & 2,2600 & 2,1412 & 0,0513 \\
GMD & 16 & 0,0456 & 0,0493 & 0,0475 & 0,0010 \\
\hline \hline
\end{tabular}

Fonte: Dados da pesquisa.

Tabela B.6- Estatística descritiva das estimativas de eficiência econômica (EE) e dos indicadores zootécnicos de eficiência da empresa VI.

\begin{tabular}{cccccc}
\hline \hline Variável & Número & Mínimo & Máximo & Média & D.Padrão \\
\hline EE(MIDMN) & 16 & 0,9661 & 0,9946 & 0,9831 & 0,0074 \\
EE(MIDEX) & 16 & 0,9769 & 0,9956 & 0,9890 & 0,0046 \\
EE(MIIDEA) & 16 & 0,9530 & 1,0000 & 0,9814 & 0,013 \\
CA & 16 & 1,9500 & 2,1000 & 2,0150 & 0,0424 \\
IDAD & 16 & 43,850 & 50,090 & 45,982 & 1,5758 \\
MOR & 16 & 4,0700 & 5,7200 & 5,0518 & 0,5366 \\
IEP & 16 & 201,64 & 243,62 & 221,54 & 11,400 \\
PM & 16 & 2,0400 & 2,4200 & 2,1600 & 0,0864 \\
GMD & 16 & 0,0440 & 0,0498 & 0,0469 & 0,0015 \\
\hline \hline
\end{tabular}

Fonte: Dados da pesquisa. 
Tabela B.7- Estatística descritiva das estimativas de eficiência econômica (EE) e dos indicadores zootécnicos de eficiência da empresa VII.

\begin{tabular}{cccccc}
\hline \hline Variável & Número & Mínimo & Máximo & Média & D.Padrão \\
\hline \hline EE(MIDMN) & 12 & 0,9700 & 0,9865 & 0,9806 & 0,0049 \\
EE(MIDEX) & 12 & 0,9805 & 0,9912 & 0,9878 & 0,0031 \\
EE(MIIDEA) & 12 & 0,9637 & 0,9844 & 0,9772 & 0,0058 \\
CA & 12 & 1,9100 & 1,9700 & 1,9333 & 0,0172 \\
IDAD & 12 & 40,090 & 42,030 & 41,030 & 0,6233 \\
MOR & 12 & 3,5700 & 5,8400 & 4,4083 & 0,6419 \\
IEP & 12 & 206,59 & 224,82 & 218,41 & 5,5128 \\
PM & 12 & 1,7800 & 1,8500 & 1,8075 & 0,0241 \\
GMD & 12 & 0,0424 & 0,0451 & 0,0440 & 0,0008 \\
\hline
\end{tabular}

Fonte: Dados da pesquisa.

Tabela B.8- Estatística descritiva das estimativas de eficiência econômica (EE) e dos indicadores zootécnicos de eficiência da empresa VIII.

\begin{tabular}{cccccc}
\hline \hline Variável & Número & Mínimo & Máximo & Média & D.Padrão \\
\hline \hline EE(MIDMN) & 16 & 0,9576 & 0,9865 & 0,9742 & 0,0085 \\
EE(MIDEX) & 16 & 0,9683 & 0,9913 & 0,9831 & 0,0067 \\
EE(MIIDEA) & 16 & 0,9317 & 0,9739 & 0,9540 & 0,012 \\
CA & 16 & 2,0700 & 2,2000 & 2,1343 & 0,0370 \\
IDAD & 16 & 47,010 & 52,130 & 49,482 & 1,4708 \\
MOR & 16 & 5,0100 & 8,6600 & 6,9031 & 1,0286 \\
IEP & 16 & 196,33 & 223,40 & 210,97 & 7,8742 \\
PM & 16 & 2,2600 & 2,5000 & 2,3918 & 0,0834 \\
GMD & 16 & 0,0457 & 0,0501 & 0,0483 & 0,0011 \\
\hline \hline
\end{tabular}

Fonte: Dados da pesquisa. 
Tabela B.9- Estatística descritiva das estimativas de eficiência econômica (EE) e dos indicadores zootécnicos de eficiência da empresa IX.

\begin{tabular}{cccccc}
\hline \hline Variável & Número & Mínimo & Máximo & Média & D.Padrão \\
\hline \hline EE(MIDMN) & 16 & 0,9809 & 0,9935 & 0,9893 & 0,0035 \\
EE(MIDEX) & 16 & 0,9881 & 0,9950 & 0,9927 & 0,0019 \\
EE(MIIDEA) & 16 & 0,9778 & 1,0000 & 0,9960 & 0,0064 \\
CA & 16 & 1,9300 & 2,0200 & 1,9687 & 0,0239 \\
IDAD & 16 & 43,000 & 46,500 & 44,450 & 1,0000 \\
MOR & 16 & 4,4900 & 7,0100 & 5,6468 & 0,7942 \\
IEP & 16 & 218,28 & 243,46 & 232,16 & 7,6591 \\
PM & 16 & 2,0200 & 2,2300 & 2,1537 & 0,0571 \\
GMD & 16 & 0,0460 & 0,0510 & 0,0484 & 0,0014 \\
\hline \hline
\end{tabular}

Fonte: Dados da pesquisa.

Tabela B.10- Estatística descritiva das estimativas de eficiência econômica (EE) e dos indicadores zootécnicos para todas as empresas.

\begin{tabular}{llllll}
\hline Variável & Número & Mínimo & Máximo & Médio & D.Padrão \\
\hline \hline EE(MIDMN) & 135 & 0,9266 & 0,9946 & 0,9790 & 0,0123 \\
EE(MIDEX) & 135 & 0,9285 & 0,9956 & 0,9856 & 0,0107 \\
EE(MIIDEA) & 135 & 0,9049 & 1,0000 & 0,9712 & 0,0212 \\
CA & 135 & 1,9100 & 2,2200 & 2,0341 & 0,0769 \\
IDAD & 135 & 40,090 & 52,130 & 45,578 & 2,6382 \\
MORT & 135 & 3,0000 & 8,6600 & 5,5732 & 1,1597 \\
IEP & 135 & 186,57 & 249,20 & 220,03 & 11,922 \\
PM & 135 & 1,7800 & 2,5500 & 2,1599 & 0,1899 \\
GPD & 135 & 0,0424 & 0,0524 & 0,0473 & 0,0021
\end{tabular}

Fonte: Dados da pesquisa. 